ORNL/TM-13370

\section{OAK RIDeE \\ NATIONAL HABORATOPY}
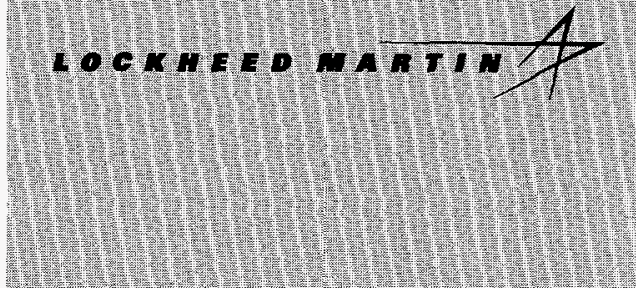

(1)

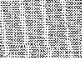

1.:

1.

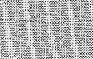

The

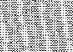

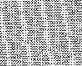
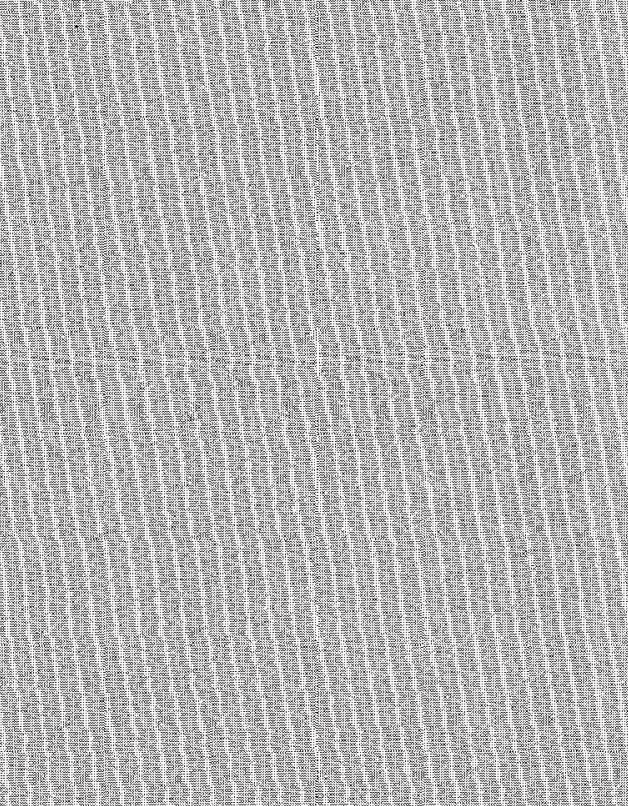

WMAGEO AND OPERATED BY

LOCKMEEO MARTII ENERGY RESEARGH CORPOHATION FOR THE UWTEO STATES DEPHRTIETT OF ENEROY

\title{
ICRF Array Module
Development and Optimization \\ ICRF Array Module
Development and Optimization for High Power Density
}

\author{
P. M. Ryan \\ D. W. Swain
}

$$
\begin{gathered}
\text { FEB } 201997 \\
\text { OSTI }
\end{gathered}
$$


This report has been reproduced directly from the best available copy.

Available to DOE and DOE contractors from the Office of Scientific and Technical Information, P. O. Box 62, Oak Ridge, TN 37831; prices available from (423) 576-8401, FTS 626-8401.

Available to the public from the National Technical Information Service, U.S. Department of Commerce, 5285 Port Royal Road, Springfield, VA 22161.

This report was prepared as ar account of work sponsored by an agency of the United States Government. Neither the United States Government nor any agency thereof, nor any of their employees, makes any warranty, express or implied, or assumes any legal liability or responsibility for the accuracy, completeness, or usefulness of any information, apparatus, product, or process disclosed, or represents that its use would not infringe privately owned rights. Reference herein to any specific commercial product, process, or service by trade name, trademark, manufacturer, or otherwise, does not necessarily constitute or imply its endorsement, recommendation, or favoring by the United States Government or any agency thereof. The views and opinions of authors expressed herein do not necessarily state or reflect those of the United States Government of any agency thereof. 


\section{DISCLAIMER}

Portions of this document may be illegible in electronic image products. Images are produced from the best available original document. 
Fusion Energy Division

\section{ICRF Array Module Development and Optimization for High Power Density}

P. M. Ryan and D. W. Swain

DATE PUBLISHED: February 1997

Prepared for the Office of Fusion Energy

Budget Activity AT $601020 \mathrm{~F}$

Prepared by

OAK RIDGE NATIONAL LABORATORY

Oak Ridge, Tennnessee 37831-6285

managed by

LOCKHEED MARTIN ENERGY RESEARCH CORPORATION for the

U.S. DEPARTMENT OF ENERGY

under contract DE-AC05-96OR22464 

This is the Final Report for ITER Task T235 "ICRF Array Module Development and Optimization for High Power Density." It was submitted to the ITER Joint Central Team in partial fulfillment of the requirements of the Design Task, as ITER Document ITER/US/96/TV-RF-04, in October 1996.

This report is an account of work assigned to the U.S. Home Team under Task Agreement No G 51 TT 06 within the agreement among the European Atomic Energy Community, the Government of Japan, the Government of the Russian Federation, and the Government of the United States of America on Cooperation in the Engineering Design Activities for the International Thermonuclear Experimental Reactor ("ITER EDA Agreement") under the auspices of the International Atomic Agency (IAEA). The report has not been reviewed by the ITER Publications Office.

This report is an account of work undertaken within the framework of the ITER EDA Agreement. Neither the ITER Director, the Parties to the ITER Agreement, the U.S. DOE, the U.S. Home Team Leader, the U.S. Home Team, the IAEA or any agency thereof, or any of their employees, makes any warranty, express or implied, or assumes any legal liability or responsibility for the accuracy, completeness, or usefulness of any information, apparatus, product, or process disclosed, or represents that its use would not infringe privately owned rights. Reference herein to any specific commercial product, process, or service by trade name, trademark, manufacturer, or otherwise, does not necessarily constitute or imply its endorsement, recommendation, or favoring by the parties to the ITER EDA Agreement, the IAEA or any agency thereof.

The views and opinions of authors expressed herein do not necessarily state or reflect those of the ITER Director, the Parties to the ITER Agreement, the U.S. DOE, the U.S. Home Team Leader, the U.S. Home Team, the IAEA or any agency thereof. 
•

$-$ 


\section{CONTENTS}

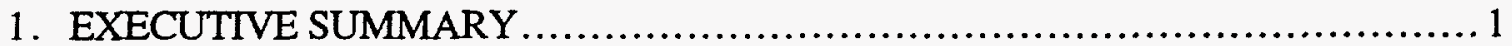

2. DESIGN TASK ...................................................................... 4

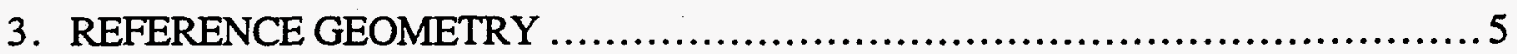

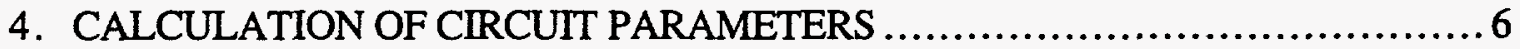

4.1 Geometry Used in ARGUS Model ...................................... 6

4.2 Electrical Characteristics for an Unslanted Faraday Shield ......................8

4.3 Electrical Characteristics for a Slanted Faraday Shield ........................8

5. TWO-DIMENSIONAL MAGNETOSTATIC AND ELECTROSTATIC (2-D

LAPLACE) CALCULATIONS ..................................................

5.1 Comparison of 2-D Laplace Calculations with ARGUS Calculations............9

5.2 Comparison of 4-Strap Array Calculations with Single-Strap (Infinite

Array) Calculations ..................................................... 10

5.3 Calculation of Capacitance and Electric Fields ..............................12

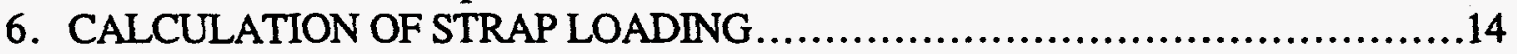

6.1 RANT3D and PLASMAIMP ..........................................14

6.2 Strap Loading Results.................................................15

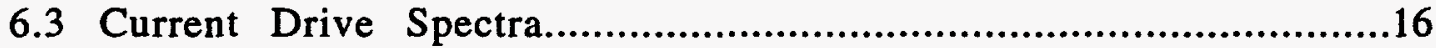

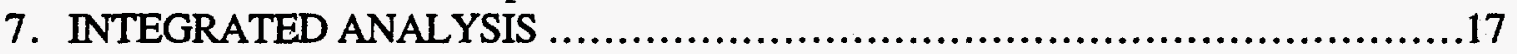

7.1 The Lossy Transmission Line Model..................................................17

7.2 Peak Voltage and Electric Fields ..........................................17

8. GEOMETRY OPTIMIZATION SUMMARY AND RECOMMENDATIONS...........22

9. THE RADIAL FEEDERS AND STUB TUNERS …..........................22 APPENDIX: DETERMINATION OF COUPLED TRANSMISSION LINE PARAMETERS FROM I, V CALCULATIONS ...............................26

A.1 Coupled Transmission Line Analysis........................................26

A. 2 Coupled Transmission Line Parameters from Currents and Voltages.............28 


\section{LIST OF FIGURES}

Figure

$\underline{\text { Page }}$

1. Peak voltage on current strap vs strap width as function of relative phasing for $60-\mathrm{MHz}$ operation ...........................................2

2. Peak parallel electric field on current strap vs strap width as a function of relative phasing for $60-\mathrm{MHz}$ operation. .........................

3. Voltage distribution along full RDL as a function of frequency for $\pi / 2$ relative phasing....................................................... 3

4. Current distribution along full RDL as function of frequency for $\pi / 2$ relative phasing.................................................................. 3

5. Nominal dimensions of antenna geometry ................................. 5

6. Dimensions of rectangularized antenna model used by ARGUS …..............7

7. ARGUS 4-strap model with slanted Faraday shield ........................... 7

8. Geometry used by magnetostatic analysis to calculate 4-strap inductance matrix ........................................................ 9

9. Single-strap geometry used to calculate inductance matrices for

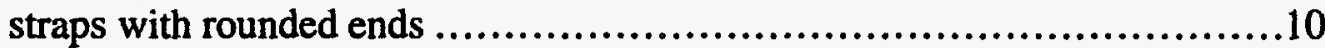

10. Contours of constant $\left|E_{\perp}\right|$ for $18 \mathrm{~cm}$ strap..................................

11. Contours of constant $\mathbb{E}_{\|} \mid$for $18 \mathrm{~cm}$ strap.............................................13

12. Plasma loading vs array phase angle as a function of frequency .................15

13. Plasma loading vs strap width as a function of array phase angle .................15

14 Plasma loading vs plasma gap as a function of array phase angle ..................16

15. Comparison of wave power spectrum and array directivity for 60 $\mathrm{MHz}$ operation and 90 relative phasing for two different septa positions .....................................................................16

16. Maximum instantaneous strap current vs frequency as function of relative phase angle between adjacent straps.

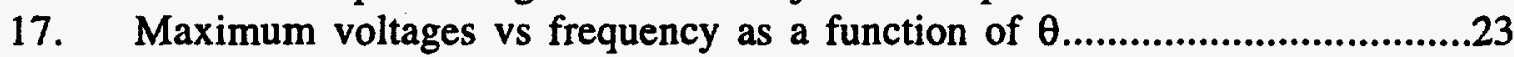

18. Peak currents on RDL vs frequency as a function of array phasing...................24

19. Characteristic impedance of 5-cm-thick feeder sections vs width, as a function of gap between feeder and cavity end walls........................24

20. Maximum electric field strength in $\mathrm{V} / \mathrm{m}$, normalized to feeder voltage, for feeder geometries of Fig. 19 


\section{EXECUTIVE SUMMARY}

This report describes the analysis and optimization of the proposed International Thermonuclear Experimental Reactor (ITER) Antenna Array for the ion cyclotron range of frequencies (ICRF). The objectives of this effort were to:

- Minimize the applied radiofrequency of voltages occurring in vacuum by proper layout and shape of components. Limit the component's surface/volumes where the if voltage is high.

- Study the effects of magnetic insulation, as applied to the current design.

- Provide electrical characteristics of the antenna for the development and analysis of tuning, arc detection/suppression, and systems for discriminating between arcs and edge-localized modes (ELMs).

- Maintain close interface with mechanical design.

The reference geometry upon which this optimization study is based is the $4 \times 2$, in-port antenna array presented at the Joint ITER JWM/CCFW Meeting in Garching (21-24 May 1996) ${ }^{1}$. The design criteria of this array is to deliver plasma heating power of 12.5 MW/port, over a frequency range of $40-80 \mathrm{MHz}$, to a plasma whose nominal surface is positioned on the order of $15 \mathrm{~cm}$ from the first wall. The essence of the optimization exercise is to minimize the voltages and electric fields occurring on the antenna structure while still providing acceptable mechanical strength, sufficient array directivity for good current drive efficiency, and a stable, controllable electrical component for the power delivery system.

The reference design was extensively analyzed with both a two-dimensional (2-D) Laplace code $^{2}$ and a three-dimensional (3-D) electromagnetic code (ARGUS) ${ }^{3}$, and its electrical characteristics were determined. Changes in these electrical characteristics with system geometry changes were then studied with the 2-D Laplace code. The parameters of interest are the strap inductance and capacitance (alternatively, the strap impedance and wave propagation velocity), and the mutual inductance between neighboring straps. The plasma loading resistance was determined by RANT3D 4 , a 3-D cold-plasma coupling code.

Using these parameters, a lossy transmission model yielded the maximum strap voltage for full power delivered to the plasma, as a function of frequency and phase as the strap dimensions and septa positions were varied. The maximum electric fields, parallel and perpendicular to the magnetic field lines, were also calculated by the 2-D Laplace code. For a fixed power delivered to the plasma, the outcome of this exercise can be summarized as follows:

- Wide straps decrease the peak voltages and electric fields on the strap ends.

- Thick straps $(5 \mathrm{~cm})$ have lower peak voltages and electric fields than thin straps $(4 \mathrm{~cm})$.

- Septum position has negligible effect on peak fields for given power.

- Peak fields increase as the phase angle between adjacent straps increases.

- Peak fields as a function of frequency are slightly higher at $60 \mathrm{MHz}$ than at 40 or $80 \mathrm{MHz}$. 
The recommended geometry includes current straps that are $5 \mathrm{~cm}$ thick, are at least $22 \mathrm{~cm}$ wide, and have rounded ends; the solid septa should be extended flush with the rear of the current strap, $11 \mathrm{~cm}$ from the first wall. The wide, thick straps reduce the voltages and electric fields for a given delivered power. The extended septa reduce the mutual coupling between straps and allow for shorter, stronger Faraday shield elements, without appreciably degrading the array directivity for current drive.

The reasons for choosing the wider straps are illustrated in Figs. 1 and 2. The peak voltage occurring on the strap for $12.5 \mathrm{MW}$ per port at $60 \mathrm{MHz}$ is shown in Fig. 1; the septum end is at $11 \mathrm{~cm}$ from the first wall, and the plasma gap is $15 \mathrm{~cm}$. Note that at frequencies below $80 \mathrm{kV}$, this peak voltage on the current strap is lower than the peak voltage in the rf system. Wider straps yield lower voltages for the same power to the plasma; the peak strap voltages increase for larger relative phase angles between the straps due to reduced plasma loading. Figure 2 shows a similar trend with the peak parallel electric fields on the strap for the same conditions.

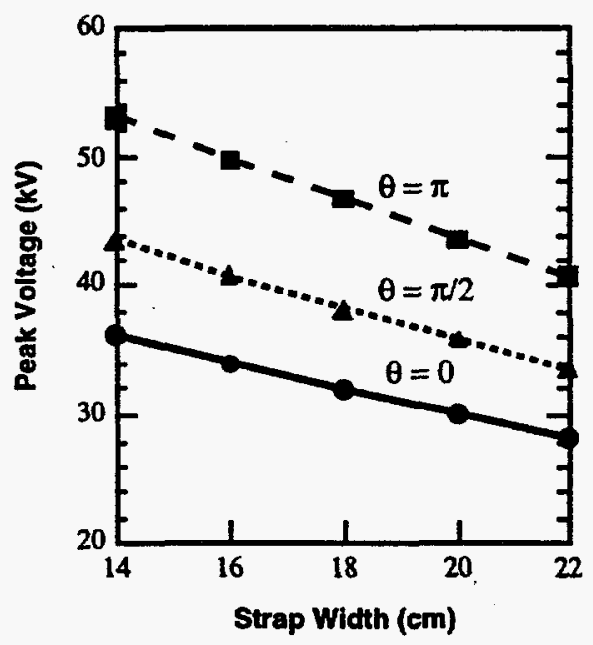

Fig. 1. Peak voltage on current strap vs strap width as function of relative phasing for 60-MHz operation. Power is 12.5 MW per port; plasma gap is $15 \mathrm{~cm}$.

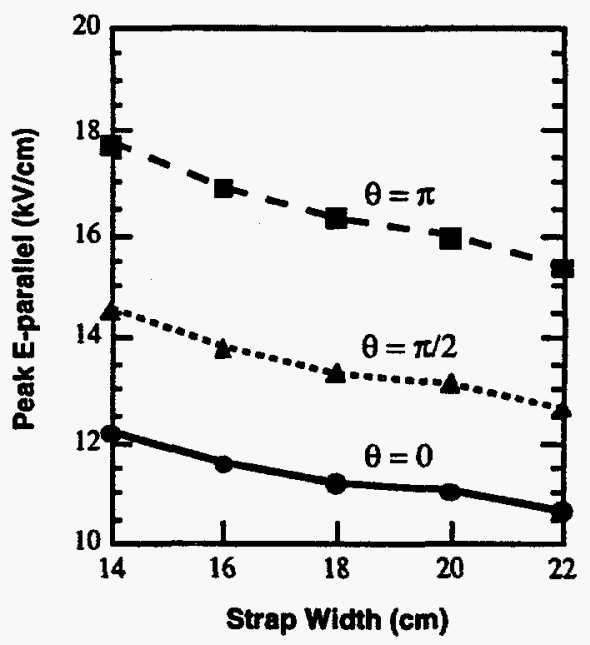

Fig. 2. Peak parallel electric field on current strap vs strap width as a function of relative phasing for $60-\mathrm{MHz}$ operation. Fower is $12.5 \mathrm{MW}$ per port; plasma gap is $15 \mathrm{~cm}$.

The impedance of the feeder sections and the stub tuners at the top and bottom of the antenna have not yet been specified nor optimized, but will have an important effect on the overall system reliability. Figures 3 and 4 show the voltage and current distributions over the entire resonant double loop (RDL) for the recommended strap/antenna box geometry as a function of frequency. At frequencies between 40 and $60 \mathrm{MHz}$, the peak voltage occurs near the end of the stub tuner; at frequencies between 60 and $80 \mathrm{MHz}$, it occurs in the radial feeder section. The impedance of the radial feeder has been taken to be $50 \Omega$ in this case; the last section of this report evaluates the potential range of impedance available for this component. 


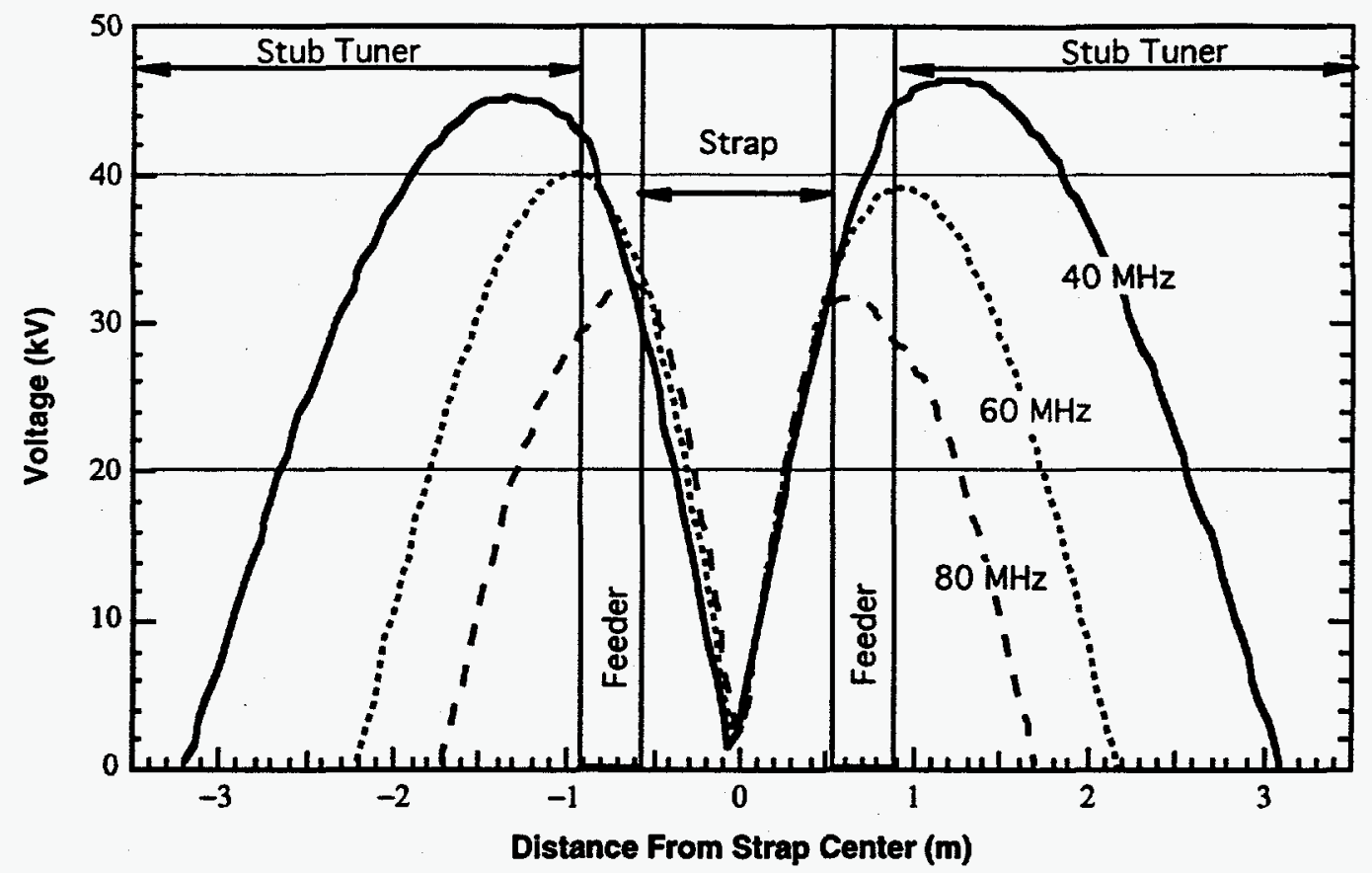

Fig. 3. Voltage distribution along full RDL as function of frequency for $\pi / 2$ relative phasing and $12.5 \mathrm{MW} /$ port delivered to plasma $15 \mathrm{~cm}$ from first wall. Impedance of stub tuner and radial feeder sections have been chosen to be 20 and $50 \Omega$, respectively, with $\mathbf{v}_{\text {phase }}=\mathrm{c}$.

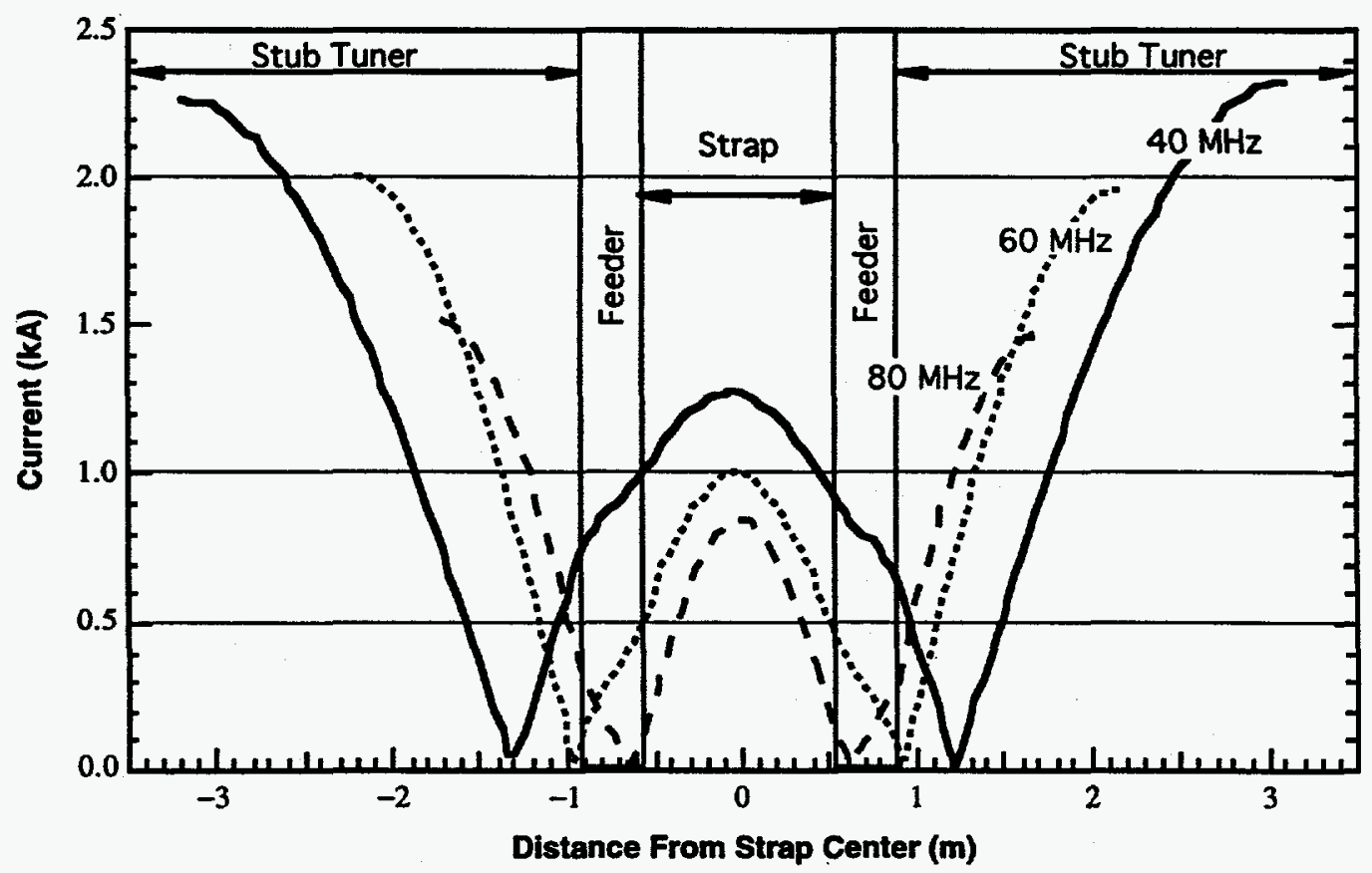

Fig. 4. Current distribution along full RDL as function of frequency for $\pi / 2$ relative phasing and $12.5 \mathrm{MW} /$ port delivered to plasma $15 \mathrm{~cm}$ from first wall. Poloidal midpoint of strap is at $y=0$. 
The impedance of the stub tuner is taken to be $20 \Omega$, with a phase velocity equal to the speed of light. Reduction of the propagation velocity in the stub tuner section will reduce the mechanical lengths in this component, but not the magnitude of the voltages or currents. The high voltage applied to the ends of this relatively low characteristic impedance section results in large current at the movable short, particularly in the $40 \mathrm{MHz}$ case. Attention should be given to increasing the impedance of this section to the extent compatible with other design constraints.

\section{DESIGN TASK}

The task of optimizing the geometry of the ITER RDL antenna array for ion cyclotron heating has concentrated on the components internal to the antenna cavity, primarily the current straps and the septa between the current straps. Analysis of the Faraday shield geometry was a task that overlapped this exercise and is documented in a separate report ${ }^{5}$. Optimization of the slow-wave stub tuners was not part of this task, although their influence on performance is discussed.

The starting point for this optimization exercise was the design presented at the ITER Design Meeting in May, 1996', cited as the base or reference geometry. The design goal was to maximize the operational reliability of the system by minimizing the voltages and electric fields occurring on the current strap, particularly the E-field component parallel to magnetic field lines, while delivering full power to the plasma. The control parameters were the current strap width, thickness, and shape, and the septum position. The strap position with respect to the Faraday shield was also studied in the initial stages of the task, but the results are not included in this report; it was felt that the 2-cm strap-to-shield gap used in the reference design was a good choice that met all design criteria, and alternatives were not further pursued.

The optimization procedure carried out the following analysis steps as the antenna geometry was adjusted:

1. The current strap inductance $\left(L^{\prime}\right)$ matrix is calculated with a magnetostatic (2-D Laplace) analysis, in the absence of a Faraclay shield.

2. The current strap capacitance (C) matrix is calculated with an electrostatic (2-D Laplace) analysis, using a conducting plane in place of the Faraday shield. The same analysis provides the parallel and perpendicular electric field components, normalized to the strap voltage.

3. The total power delivered to the plasma as a function of strap width, septum location, relative phasing, operating frequency, and plasma gap is calculated by the RANT3D code. The driving current is normalized to $1 \mathrm{~A}$ peak, and the nominal phase velocity along the strap is assumed to be $0.7 c$.

4. The equivalent plasma loading resistance per unit length $R^{\prime}$ for the antenna straps is calculated from the total power delivered to the plasma; the nominal characteristics of the transmission line used in this transformation are $Z_{0}=40 \Omega$ and $\beta=0.7 c$. 
5. A lossy transmission line model of the antenna, characterized by the $R^{\prime}, \mathrm{L}^{\prime}$, and $\mathrm{C}^{\prime}$ matrices calculated in previous steps, is used to compute the current and voltage along the strap for full power (12.5-MW/port) operation.

6. The peak strap voltage found in step 5 is combined with the E-fields per strap volt found in step 2 to give the absolute magnitude of the maximum E-field components on the current strap for full power operation.

The antenna geometry that yields the minimum E-field parallel to magnetic field lines at full power is the one recommended. However, it is recognized that many other engineering constraints, with regard to mechanical, thermal, fabrication, and vessel integration issues, will enter into the final design of the antenna. To that end we provide detailed tables to provide information concerning the consequences of subsequent design choices on the electrical performance of the antenna.

\section{REFERENCE GEOMETRY}

As noted previously, the reference geometry used in these optimization studies is based on the geometry presented at the Garching meeting in May, 1996. Figure 5 shows the nominal dimensions of the reference geometry in the $x-z$ (radial-toroidal) plane; the width and thickness of the straps and the radial extent of the solid septa are subject to adjustment in these optimization exercises.

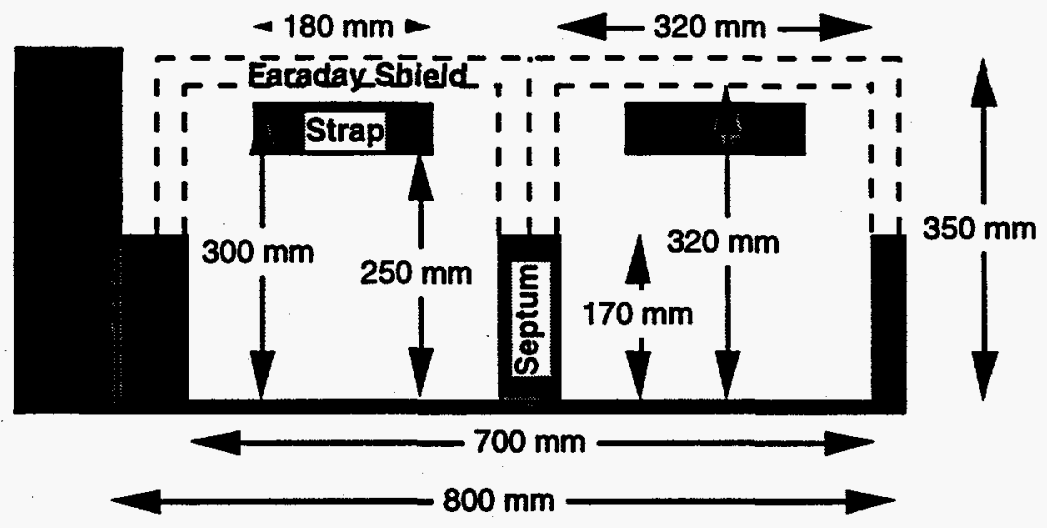

Fig. 5. Nominal dimensions of antenna geometry. Only two (outer and inner) of four straps in toroidal direction are shown (toroidal symmetry assumed).

The antenna array geometry has been rectangularized for RANT3D plasma loading calculations. The ARGUS and 2-D Laplace codes use similarly rectangularized geometries for convenience, gridding accuracy, and comparison purposes. Slight differences in the dimensions were used for each phase of the study; these values are listed in Table 1, with radial dimensions referenced to the first wall. Some of these geometry differences are historical (i.e., the state of the reference design when the models were constructed), and some are due to gridding constraints. The most significant difference is in the poloidal height of the antenna; ARGUS uses $106 \mathrm{~cm}$ and RANT3D uses $116 \mathrm{~cm}$. The RANT3D antenna height was retained from previous studies ${ }^{6}$ for direct power comparisons, while 
the ARGUS antenna height was dictated by the center-to-center spacing of the 24-cm-diam feed ports and a manageable grid spacing.

These slight dimension differences are not considered significant in the process of antenna optimization. The antenna parameters for detailed, accurate geometries are calculated by the 2-D Laplace analysis and checked for a few simplified, canonical cases against the ARGUS code. These characteristic antenna parameters are used in conjunction with the RANT3D plasma loading results, which are not very sensitive to slight geometric variations, to generate the voltages and electric fields for a given power to the plasma from a transmission line model of the antenna.

Table 1. Antenna geometry dimensions used in optimization study

\begin{tabular}{|c|c|c|c|}
\hline & $\begin{array}{l}\text { RANT3D } \\
(\mathrm{cm})\end{array}$ & $\begin{array}{l}\text { ARGUS } \\
\text { (cm) }\end{array}$ & $\begin{array}{l}\text { 2-D Laplace } \\
\text { (cm) }\end{array}$ \\
\hline First wall & 0.0 & 0.0 & 0.0 \\
\hline Front of Faraday shield & NA & 1.5 & NA \\
\hline Rear of Faraday shield & NA & 4.5 & NA \\
\hline Front of current strap & 6.0 & 6.5 & 5.5 \\
\hline Rear of current strap & 11.0 & 11.5 & 9.5 and 10.5 \\
\hline Septa ends & 11 and 19 & 11 and 19.5 & 10.5 and 19.5 \\
\hline Rear wall of cavity & 32 & 36 & 31.5 and 35.5 \\
\hline Current strap width & 14 to 22 & 18 & 14 to 22 \\
\hline Septa width & 7 & 6 & 7 \\
\hline Inner Cavity width & 31 & 32 & 31 \\
\hline Port width & 160 & 160 & 160 \\
\hline Cavity height & 123 & 130 & NA \\
\hline Strap height & 116 & 106 & NA \\
\hline
\end{tabular}

\section{CAlCUlation OF CIRCUIT PaRAMETERS FROM THE ARGUS MODEL}

\subsection{Geometry Used in ARGUS Model}

The main purpose of the full 3-D electromagnetic analysis of the antenna geometry using the ARGUS code was to provide vacuum E-field distributions for if sheath analysis by Lodestar Research ${ }^{5}$. Secondary purposes were to serve as a point of comparison with the results of the 2-D Laplace analysis and to quantify the effect that tilting the Faraday shield rods has on the electrical characteristics of the antenna straps.

A side view of the rectangularized model of the ITER antenna is shown in Fig. 6. The rectangular Faraday shield elements have 3- by 5 -cm cross sections and are spaced 5 $\mathrm{cm}$ apart (50\% transparent). The radial feed is represented by a 12 -cm-diam section connecting the poloidal midpoint of the strap with the rear wall. The driving terms for this model are the voltages applied at the upper and lower ports (14-cm ID and 24-cm OD, for a 
$\sim 30-\Omega$ characteristic impedance), which would be connected to the end-tuners. Driving the antenna with equal magnitude, out-of-phase voltages at the upper and lower ports results in a virtual ground at the poloidal midpoint. This approach avoids the complication of modeling the long end-tuner sections of the RDL. It gives the same current and voltages distributions and electromagnetic fields as would obtain for an RDL antenna matched at a slightly off-center feed point, with the end-tuners adjusted to provide both resonance at the drive frequency and a virtual ground at the poloidal midpoint of the strap.

Most of the ARGUS runs were made using one 2-strap quadrant of the full 8-strap array. Metallic (antisymmetric) boundary conditions (BCs) on the lower poloidal symmetry plane were used to represent lower straps operating in phase with the upper straps. Both symmetric and antisymmetric BCs were applied in turn to the toroidal symmetry plane to obtain the four independent phasing cases needed to generate the $4 \times 4$ coupling matrices. Symmetric BCs give $0-0-0-0$ and $0-\pi-\pi-0$ phasings, while antisymmetric $B C s$ give the $0-0-\pi-\pi$ and $0-\pi-0-\pi$ cases. In the case of slanted Faraday shields, all four straps were modeled because toroidal symmetry was no longer present (Fig. 7). The 4-strap model was also used with the unslanted Faraday shield to obtain the current drive $(0-\pi / 2-\pi-3 \pi / 2)$ fields for the rf sheath study.

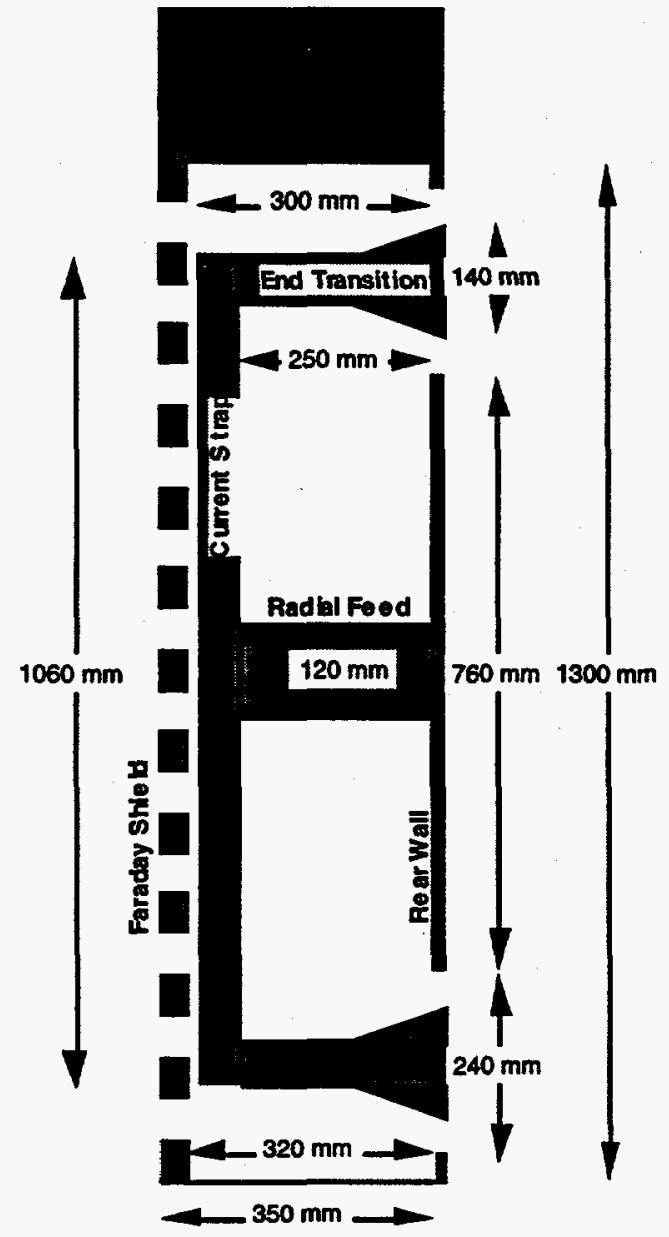

Fig. 6. Dimensions of rectangularized antenna model used by ARGUS code.

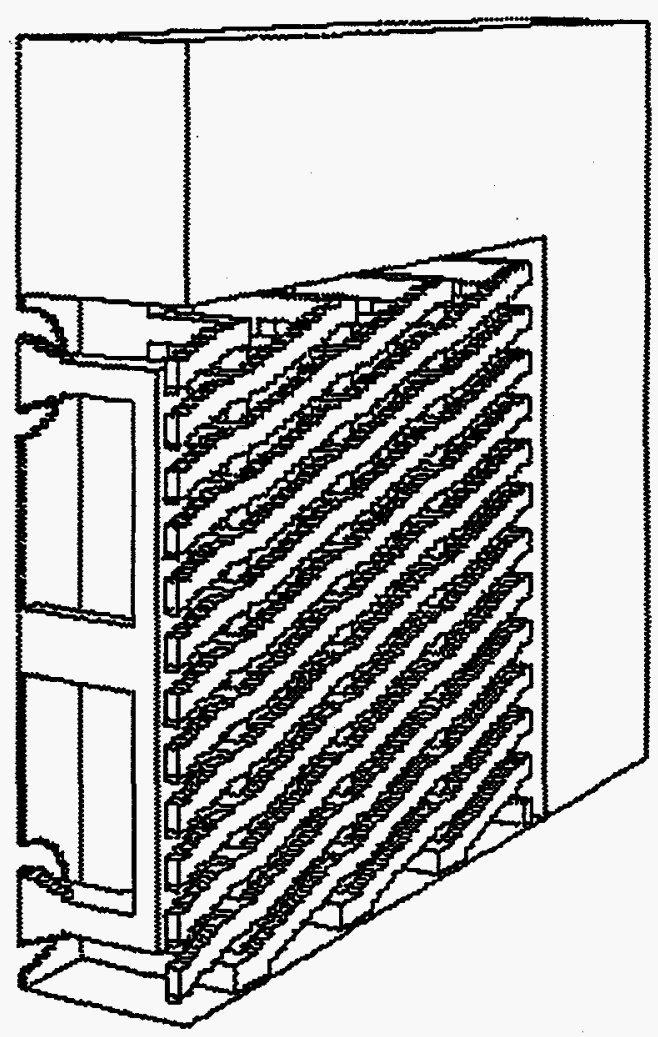

Fig. 7. ARGUS 4-strap model with slanted Faraday shield, cut to expose the center of fourth strap. 


\subsection{Electrical Characteristics for an Unslanted Faraday Shield}

The strap currents and voltages $(I, V)$ are found at two locations along the strap, at the strap ends and at the poloidal midpoint (virtual ground), for each of four independent strap phasings. These $I, V$ matrices are used to generate the antenna impedance and admittance matrices $\mathbf{Z}, \mathbf{Y}$ (or the equivalent inductance and capacitance matrices $L^{\prime}, C$ ), as outlined in the Appendix. Table 2 details the principal features of the antenna characteristics for two different positions of the septum ends, at 11 and $19.5 \mathrm{~cm}$ from the first wall. The nominal "self" inductance and capacitance per unit length, $L_{0}$ " and $C_{0}$ ", are the diagonal elements of the $L^{\prime}, C^{\prime}$ matrices [see Eqs. (A7) and (A8) in the Appendix]. The inductive coupling coefficient $k_{\mathrm{mn}}=L_{\mathrm{mn}}{ }^{\prime}\left(L_{\mathrm{mm}}{ }^{\prime} L_{\mathrm{nn}}\right)^{-1 / 2}$ quantifies the mutual inductance between straps $\mathrm{m}$ and $\mathrm{n}$. Extending the solid septa $8.5 \mathrm{~cm}$ closer to the straps has negligible effect on the strap capacitance and decreases the strap inductance slightly, thus decreasing the strap impedance and increasing the phase velocity. The most significant change is in the inductive coupling coefficient between adjacent straps, which is reduced by a factor of 2.5.

Care should be taken in the interpretation of the nominal characteristic strap impedance $Z_{0}$ and the relative phase velocity $v_{p h} / c$ given in Table 2 . The $Z_{0}$ of each strap is the corresponding diagonal element of the $\mathbf{Z}_{\text {strap }}$ matrix defined by Eq. (A49) and is equal to $\left(L_{0}{ }^{\prime} / C_{0}\right)^{1 / 2}$, and the accompanying phase velocity is equal to $\left(L_{0}{ }^{\circ} C_{0}\right)^{-1 / 2}$. This is a common method of characterizing antennas and is offered for the sake of comparison with previous calculations. Because of mutual coupling between straps, the strap inductance and, to a lesser extent, capacitance are influenced by the magnitude and relative phase of currents and voltages in neighboring straps. This change of strap impedance and phase velocity with antenna phasing is taken into account when analyzing the expected voltages and electric fields for full power operation.

Table 2. Current strap circuit parameters of the reference geometry from a coupled transmission line analysis of the strap $I$ and $V$ calculated by ARGUS.

\begin{tabular}{|c|c|c|c|c|c|c|}
\hline Septum $(\mathbf{c m})$ & Strap & $\mathbf{L}_{0^{\prime}}(\mathbf{H} / \mathbf{m})$ & $\mathbf{C}_{0^{\prime}}(\mathbf{F} / \mathbf{m})$ & $\mathrm{Z}_{0}(\Omega)$ & $\mathbf{v}_{\mathbf{p h}} / \mathbf{c}$ & $\mathbf{k}(\%)$ \\
\hline 19.5 & Outer & $2.571 \times 10^{-7}$ & $1.25\left(\times 10^{-10}\right.$ & 45.33 & 0.588 & $\mathrm{k}_{12}=14.3$ \\
& Inner & $2.775 \times 10^{-7}$ & $1.237 \times 10^{-10}$ & 47.43 & 0.569 & $\mathrm{k}_{23}=14.6$ \\
\hline 11 & Outer & $2.201 \times 10^{-7}$ & $1.221 \times 10^{-10}$ & 42.46 & 0.643 & $\mathrm{k}_{12}=5.4$ \\
& Inner & $2.272 \times 10^{-7}$ & $1.226 \times 10^{-10}$ & 43.04 & 0.632 & $\mathrm{k}_{23}=6.1$ \\
\hline
\end{tabular}

\subsection{Electrical Characteristics for a Slanted Faraday Shield}

The electrical characteristics shown in Table 2 are for a model with an unslanted Faraday shield. Cases were also run for a model with a Faraday shield whose elements were slanted at an angle of $17.4^{\circ}$ with respect to the horizontal (Fig. 7). The slanted shield reduced the strap impedance by approximately $1.5 \%$. We conclude that the electrical characteristics of the antenna will not be affected by this degree of shield slanting. 


\section{TWO-DIMENSIONAL MAGNETOSTATIC AND ELECTROSTATIC (2-D LAPLACE) CALCULATIONS}

\subsection{Comparison of 2-D Laplace Calculations with ARGUS Calculations}

The transmission line inductance and capacitance values used in the strap geometry optimization were calculated with a 2-D Laplace analysis, employing single straps in an "infinite array" geometry. This approach allowed more accurate modeling of strap shapes because it was possible to employ finer, denser solution grids with single straps in 2-D than with multiple straps in 3-D. Some multiple-strap 2-D cases were run to provide points of comparison between the codes. In Table 3, the values computed from the 2-D Laplace analysis for the rectangular 4-strap geometry of Fig. 8 are compared with the ARGUS results for a similar rectangular strap geometry. Here the inductance was calculated with a magnetostatic analysis without a Faraday shield, and the capacitance was calculated with an electrostatic analysis with a conducting boundary placed at the inner surface of the Faraday shield. A 3-D magnetostatic analysis ${ }^{7}$ was also run to calculate the reduction in inductance due to the magnetic shielding effect of the Faraday shield. The inductance was reduced by about $10 \%$ for this shield geometry, and this reduction factor has been applied to all subsequent 2-D inductance calculations. The expected reduction in capacitance due to the transparency of the Faraday shield has been neglected in these and subsequent calculations.

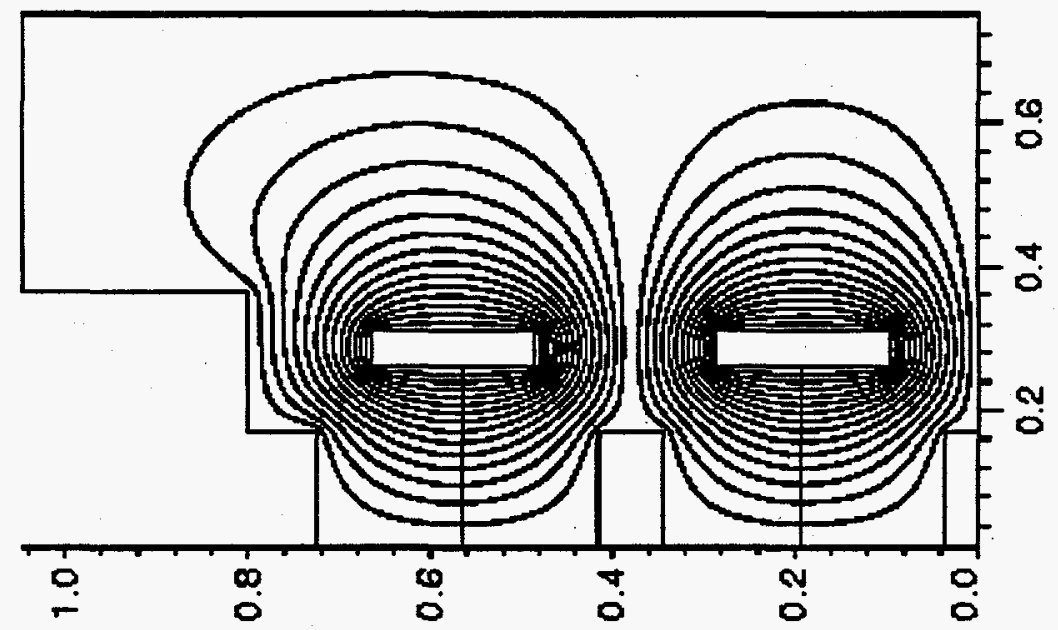

Fig. 8. Geometry used by magnetostatic analysis to calculate 4-strap inductance matrix. Contours of constant poloidal vector potential (proportional to poloidal Efield) are shown for dipole $(\pi)$ phasing case. 
Table 3. Comparison of 4-strap circuit parameters calculated from ARGUS results and from 2-D Laplace analyses (septa at $19.5 \mathrm{~cm}$ )

\begin{tabular}{|c|c|c|c|c|c|c|}
\hline Analysis & Strap & $\mathrm{L}_{0^{\prime}}(\mathbf{H} / \mathbf{m})$ & $\mathrm{C}_{0^{\prime}}(\mathrm{F} / \mathbf{m})$ & $\mathrm{Z}_{0}(\Omega)$ & $\mathbf{v}_{\mathbf{p h}} / \mathbf{c}$ & $\mathbf{k}(\%)$ \\
\hline ARGUS & Outer & $2.57 \times 10^{-7}$ & $1.250 \times 10^{-10}$ & 45.3 & 0.588 & $\mathrm{k}_{12}=14.3$ \\
& Inner & $2.78 \times 10^{-7}$ & $1.237 \times 10^{-10}$ & 47.4 & 0.569 & $\mathrm{k}_{23}=14.6$ \\
\hline 2-D Laplace & Outer & $2.56 \times 10^{-7}$ & $1.281 \times 10^{-10}$ & 44.7 & 0.582 & $\mathrm{k}_{12}=13.8$ \\
& Inner & $2.72 \times 10^{-7}$ & $1.281 \times 10^{-10}$ & 46.1 & 0.565 & $\mathrm{k}_{23}=14.4$ \\
\hline
\end{tabular}

\subsection{Comparison of 4-Strap Array Calculations With Single-Strap (Infinite Array) Calculations}

As mentioned above, the inductance and capacitance matrices used in the geometry optimization process were calculated for single straps, using BCs that simulated an infinite array in the toroidal direction, as demonstrated in Fig. 9. Figure 9(a) shows the E-poloidal contours for monopole operation (with symmetric or Neumann BCs), and Fig. 9(b) shows dipole operation (with metallic or Dirichlet BCs). The validity of this infinite-strap approximation to the actual 4-strap geometry is tested by comparing the infinite-strap values to the inner strap values in the geometry of Fig. 8. A rectangular 18- by 5-cm strap in the infinite array geometry of Fig. 9 has a self-inductance of $2.86 \times 10^{-7} \mathrm{H} / \mathrm{m}$ and a coupling

(a)

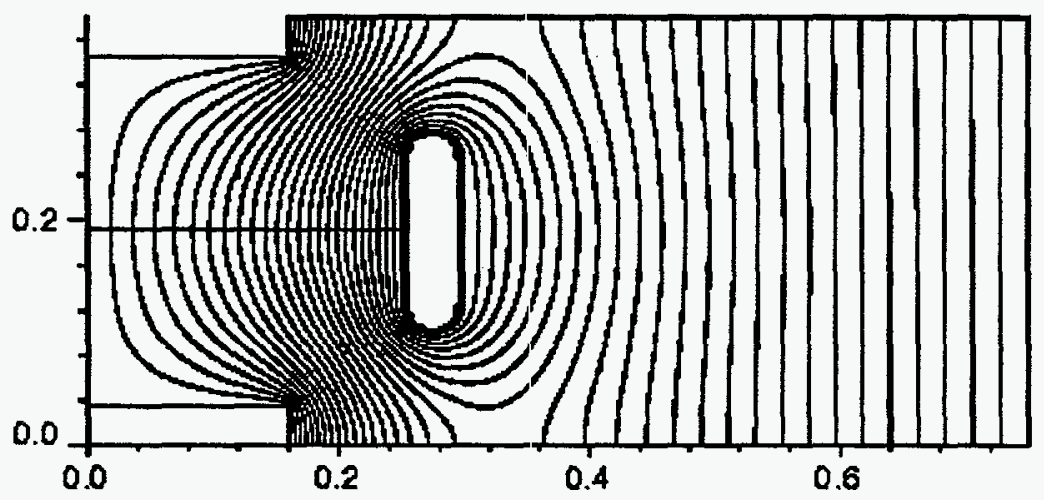

(b)

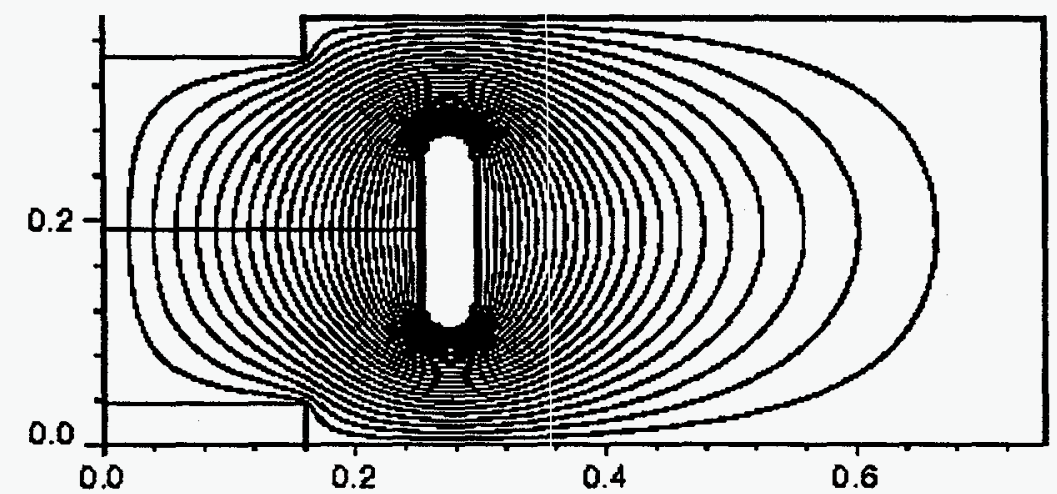

Fig. 9. Single-strap (infinite array) geometry used to calculate inductance matrices for straps with rounded ends (this example has septa at $19.5 \mathrm{~cm}$, cavity rear at 35.5 cm). Constant E-poloidal contours for monopole (top) and dipole (bottom) phasing are shown. 
coefficient of $13.9 \%$. This compares with a self-inductance of $2.72 \times 10^{-7} \mathrm{H} / \mathrm{m}$ and a coupling coefficient of $14.4 \%$ for the inner strap in the geometry of Fig. 8.

The inductive coupling matrix for the infinite-strap array was calculated for two different strap thicknesses ( 4 and $5 \mathrm{~cm}$ ) as the strap width is varied between 14 and $22 \mathrm{~cm}$; the results are shown in Tables 4-6. Tables 4 and 5 have the ends of the solid septa located at $19.5 \mathrm{~cm}$ from the first wall, or $9 \mathrm{~cm}$ behind the rear of the $5-\mathrm{cm}$-thick strap $(10 \mathrm{~cm}$ behind the 4-cm-thick strap). The large distance between the current strap and the end of the septum is responsible for relatively high inductance and mutual coupling and allows the proximity of the rear wall to influence the strap inductance. The rear wall is $4 \mathrm{~cm}$ closer to the strap in Table 5 than in Table 4, and the inductance and mutual coupling are somewhat lower. The septum is at $11 \mathrm{~cm}$ in Table 6, flush with the rear of the 5-cm-thick strap, and the position of the rear wall no longer plays an important role in the electrical characteristics. The proximity of the septum to the current strap in the geometry of Table 6 dominates the electrical response and reduces the inductance and mutual coupling.

The significant geometric results are that increasing the width of the current strap reduces the inductance significantly, while decreasing the thickness increases the inductance only slightly. The current straps have rounded ends, with a radius of curvature equal to half the strap thickness. Rounding the strap tips increases the inductance somewhat, as can be seen by comparing the 18-cm rounded end straps in Tables 4-6 with the 18-cm rectangular end straps (highlighted in bold). The nominal impedance and phase velocity for each strap shape are also given in Tables 4-6; the calculation of the capacitance per unit length, which determines these characteristics, is discussed in the next section.

Table 4. Septum at $19.5 \mathrm{~cm}$, cavity rear at $35.5 \mathrm{~cm}$, and rounded ends (squared ends in bold)

\begin{tabular}{|c|c|c|c|c|c|}
\hline Thickness (cm) & Width $(\mathrm{cm})$ & $\mathbf{L}_{0}{ }^{\prime}(\mathrm{H} / \mathrm{m})$ & $\mathbf{k}(\%)$ & $\mathrm{Z}_{\mathbf{Q}(\Omega)}$ & $\mathbf{V}_{\mathrm{ph}} / \mathbf{c}$ \\
\hline 5.00 & 14.00 & $3.321 \times 10^{-7}$ & 11.3 & 58.832 & 0.590 \\
& 16.00 & $3.132 \times 10^{-7}$ & 12.2 & 52.078 & 0.554 \\
& 18.00 & $2.970 \times 10^{-7}$ & 13.2 & 50.106 & 0.562 \\
& 18.00 & $2.862 \times 10^{-7}$ & 13.9 & 47.264 & $\mathbf{0 . 5 5 1}$ \\
& 20.00 & $2.821 \times 10^{-7}$ & 14.3 & 46.520 & 0.550 \\
& 22.00 & $2.683 \times 10^{-7}$ & 15.6 & 44.747 & 0.556 \\
\hline 4.00 & 14.00 & $3.439 \times 10^{-7}$ & 11.3 & 59.918 & 0.581 \\
& 16.00 & $3.253 \times 10^{-7}$ & 12.3 & 55.229 & 0.566 \\
& 18.00 & $3.085 \times 10^{-7}$ & 13.3 & 51.176 & 0.553 \\
& 20.00 & $2.933 \times 10^{-7}$ & 14.4 & 47.574 & 0.541 \\
& 22.00 & $2.793 \times 10^{-7}$ & 15.7 & 45.771 & 0.546 \\
\hline
\end{tabular}


Table 5. Septum at $19.5 \mathrm{~cm}$, cavity rear at $31.5 \mathrm{~cm}$, and rounded ends (squared ends in bold)

\begin{tabular}{|c|c|c|c|c|c|}
\hline Thickness $(\mathbf{c m})$ & Width $(\mathbf{c m})$ & $\mathbf{L}_{0^{\circ}}(\mathbf{H} / \mathbf{m})$ & $\mathbf{k}(\%)$ & $\mathbf{Z}_{0}(\Omega)$ & $\mathbf{v}_{\text {ph }} / \mathbf{c}$ \\
\hline 5.00 & 14.00 & $3.014 \times 10^{-7}$ & 8.0 & 56.047 & 0.620 \\
& 16.00 & $2.825 \times 10^{-7}$ & 8.7 & 49.457 & 0.584 \\
& 18.00 & $2.652 \times 10^{-7}$ & 9.5 & 47.354 & 0.595 \\
& $\mathbf{1 8 . 0 0}$ & $\mathbf{2 . 5 4 1 \times 1 0 ^ { - 7 }}$ & $\mathbf{1 0 . 0}$ & $\mathbf{4 4 . 5 3 5}$ & $\mathbf{0 . 5 8 4}$ \\
& 20.00 & $2.493 \times 10^{-7}$ & 10.4 & 43.739 & 0.577 \\
& 22.00 & $2.345 \times 10^{-7}$ & 11.4 & 41.834 & 0.595 \\
\hline 4.00 & 14.00 & $3.141 \times 10^{-7}$ & 8.2 & 57.215 & 0.607 \\
& 16.00 & $2.947 \times 10^{-7}$ & 8.9 & 50.513 & 0.571 \\
& 18.00 & $2.771 \times 10^{-7}$ & 9.7 & 48.403 & 0.582 \\
& 20.00 & $2.610 \times 10^{-7}$ & 10.7 & 44.750 & 0.572 \\
& 22.00 & $2.461 \times 10^{-7}$ & 11.7 & 42.853 & 0.580 \\
\hline
\end{tabular}

Table 6. Septum at $10.5 \mathrm{~cm}$, cavity rear at $35.5 \mathrm{~cm}$, and rounded ends (squared ends in bold)

\begin{tabular}{|c|c|c|c|c|c|}
\hline Thickness (cm) & Width $(\mathrm{cm})$ & $\mathbf{L}_{0^{\prime}}(\mathbf{H} / \mathbf{m})$ & $\mathbf{k}(\%)$ & $\mathbf{Z}_{0}(\Omega)$ & $\mathbf{v}_{\mathbf{p h}} / \mathbf{c}$ \\
\hline 5.00 & 14.00 & $2.735 \times 10^{-7}$ & 4.6 & 53.386 & 0.651 \\
& 16.00 & $2.527 \times 10^{-7}$ & 5.0 & 46.777 & 0.617 \\
& 18.00 & $2.333 \times 10^{-7}$ & 5.3 & 44.410 & 0.635 \\
& $\mathbf{1 8 . 0 0}$ & $2.208 \times 10^{-7}$ & $\mathbf{5 . 6}$ & $\mathbf{4 1 . 5 1 8}$ & $\mathbf{0 . 6 2 7}$ \\
& 20.00 & $2.148 \times 10^{-7}$ & 5.7 & 40.595 & 0.630 \\
& 22.00 & $1.967 \times 10^{-7}$ & 6.1 & 38.311 & 0.649 \\
\hline 4.00 & 14.00 & $2.852 \times 10^{-7}$ & 4.8 & 54.520 & 0.637 \\
& 16.00 & $2.641 \times 10^{-7}$ & 5.2 & 47.815 & 0.604 \\
& 18.00 & $2.444 \times 10^{-7}$ & 5.6 & 45.452 & 0.620 \\
& 18.00 & $2.342 \times 10^{-7}$ & $\mathbf{5 . 8}$ & $\mathbf{4 2 . 7 5 6}$ & $\mathbf{0 . 6 0 9}$ \\
& 20.00 & $2.256 \times 10^{-7}$ & 6.0 & 41.607 & 0.615 \\
& 22.00 & $2.076 \times 10^{-7}$ & 6.5 & 39.357 & 0.632 \\
\hline
\end{tabular}

\subsection{Calculation of Capacitance and Electric Fields}

The capacitance per unit length of the antenna strap is primarily determined by the width of the current strap and its spacing to the Faraday shield, very much like a parallel plate capacitor. The 2-D Laplace code, operating in the electrostatic mode on the geometry exemplified in Figs. 10 and 11, calculates the electric field distribution resulting from a voltage difference applied between the current strap and the grounded cavity, which includes the Faraday shield. The surface electric field gives the charge density distribution, from which the strap's capacitance to ground can be calculated. For convenience, the Faraday shield is taken as a perfectly conducting plane. The periodic nature of the Faraday shield elements in the poloidal direction tends to reduce this ideal capacitance somewhat; this effect is small for the Faraday shield geometry and gap under consideration and was neglected for the purposes of this optimization study. 


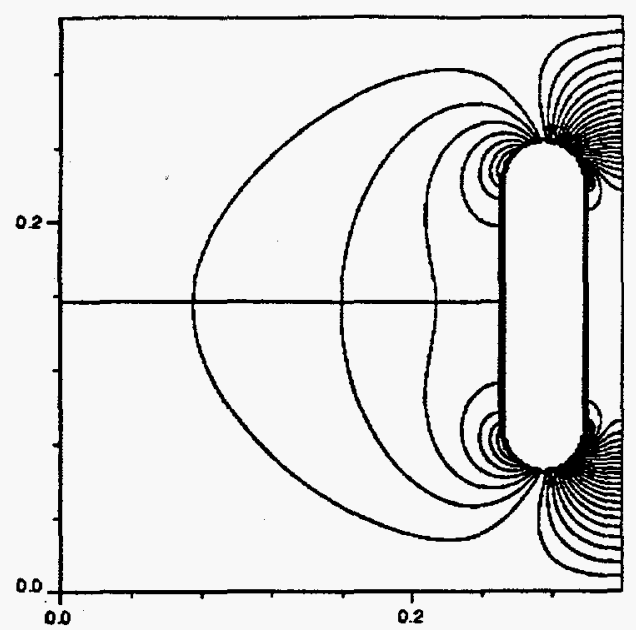

Fig. 10. Contours of constant $\left|E_{\perp}\right|$ for

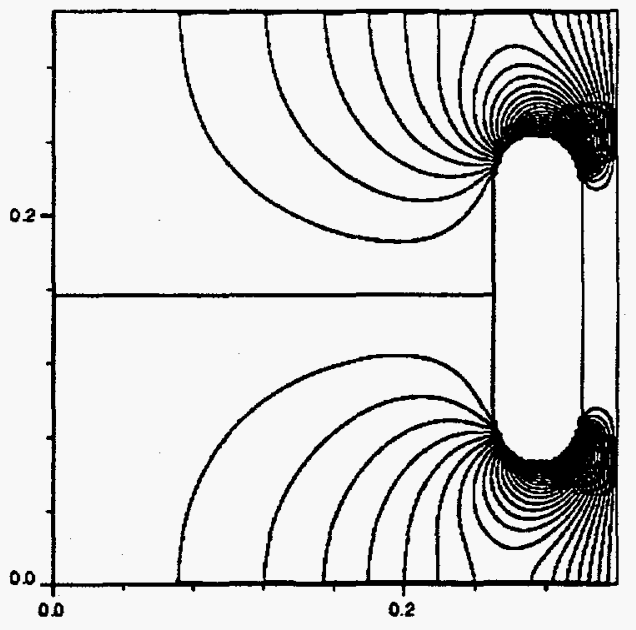

Fig. 11. Contours of constant $\left|E_{\|}\right|$for 18 cm strap. $18 \mathrm{~cm}$ strap.

The capacitance per unit length $C^{\prime}$ is given in Table 7 for strap widths of 14 to 22 $\mathrm{cm}$ and thicknesses of 4 and $5 \mathrm{~cm}$. Wider straps have higher capacitance, in accordance with the parallel plate model. Thinner straps have slightly lower capacitance for the same width, owing to slightly less area for charge storage. However, the charge density on the tips is increased for thinner straps, as can be seen by the values of the maximum E-field $\left(\max E\right.$ ) in Table 7. The values of $\max E, \max E_{\perp}$, and $\max E_{\|}$are given in units of volts per meter, normalized to $1 \mathrm{~V}$ applied between the current strap and the Faraday shield. The quantity $\xi$ is the geometric field enhancement factor, defined as the ratio of the maximum $E$ field to the parallel plate E-field; the reference parallel plate E-field for $1 \mathrm{~V}$ across a 2-cm gap is $50 \mathrm{~V} / \mathrm{m}$.

The electric field has been further separated into components that are perpendicular and parallel to the toroidal magnetic field. It has been conjectured that higher electric fields can be sustained perpendicular to magnetic field lines due to the phenomenon of magnetic insulation. Electric fields parallel to magnetic field lines enjoy no such reduction in their ability to accelerate electrons across the insulating gap; indeed, the increased path length of electrons due to gyromotion may increase the probability of ionizing events in the background gas. The ratio of perpendicular to parallel field components varies between 1.4 and 1.7. Because of this rather low ratio for the geometries investigated, the absolute magnitude of $E_{\|}$is taken to be the limiting factor on voltage holding. Efforts should be made to keep $E_{\|}$below about $20 \mathrm{kV} / \mathrm{cm}$ at full power. 
Table 7. Electric field calculations norrnalized to the voltage on the strap.

\begin{tabular}{|c|c|c|c|c|c|c|c|}
\hline $\begin{array}{c}\text { Thick } \\
(\mathbf{c m})\end{array}$ & $\begin{array}{c}\text { Width } \\
(\mathbf{c m})\end{array}$ & $\begin{array}{c}\mathbf{C}^{\prime} \\
(\mathbf{F} / \mathbf{m})\end{array}$ & $\begin{array}{c}\max \mathbf{E} \\
\left(\mathbf{V} / \mathbf{m} / \mathbf{V}_{\mathbf{s}}\right)\end{array}$ & $\xi$ & $\begin{array}{c}\max \mathbf{E}_{\perp} \\
\left(\mathbf{V} / \mathbf{m} / \mathbf{V}_{\mathbf{s}}\right)\end{array}$ & $\begin{array}{c}\max \mathbf{E}_{\|} \\
\left(\mathbf{V} / \mathbf{m} / \mathbf{V}_{\mathbf{s}}\right)\end{array}$ & $\mathbf{E}_{\perp} / \mathbf{E}_{\|}$ \\
\hline 5.0 & 14.0 & $9.595 \times 10^{-11}$ & 58.350 & 1.167 & 56.865 & 33.410 & 1.70 \\
& 16.0 & $1.155 \times 10^{-10}$ & 58.300 & 1.166 & 56.934 & 33.985 & 1.68 \\
& 18.0 & $1.183 \times 10^{-10}$ & 58.225 & 1.165 & 57.311 & 34.908 & 1.64 \\
& 20.0 & $1.303 \times 10^{-10}$ & 58.058 & 1.161 & 57.454 & 36.588 & 1.57 \\
& 22.0 & $1.340 \times 10^{-10}$ & 58.776 & 1.176 & 57.138 & 37.768 & 1.51 \\
\hline 4.0 & 14.0 & $9.579 \times 10^{-11}$ & 59.584 & 1.192 & 58.329 & 38.429 & 1.52 \\
& 16.0 & $1.066 \times 10^{-10}$ & 60.835 & 1.217 & 58.710 & 38.180 & 1.54 \\
& 18.0 & $1.178 \times 10^{-10}$ & 62.450 & 1.249 & 59.972 & 40.017 & 1.50 \\
& 20.0 & $1.296 \times 10^{-10}$ & 62.488 & 1.250 & 60.200 & 39.849 & 1.51 \\
& 22.0 & $1.333 \times 10^{-10}$ & 59.872 & 1.197 & 58.411 & 42.355 & 1.38 \\
\hline
\end{tabular}

\section{CALCULATION OF STRAP LOADING}

\subsection{RANT3D and PLASMAIMP}

The plasma loading resistance per unit length is calculated with the RANT3D code, which solves Maxwell's equations in Fourier space using rectangular waveguide basis sets. Its object-oriented code structure allows complex 3-D structures to be built from nested waveguide sections while imposing $\mathbf{E}$ and $\mathbf{B}$ matches at the waveguide interfaces. The final match is made to a plasma impedance matrix that is generated by PLASMAIMP8, using a semi-infinite plasma slab model, which employs the cold-plasma dispersion relation. The density profile and plasma parameters used by PLASMAIMP are given in Table 8.

The density profile inside the separatrix is given by $n(r)=\left(n_{e o}-n_{\text {edge }}\right)\left[1-(r / a)^{2}\right] \alpha_{n}$ $+\mathrm{n}_{\text {edge}}$; outside the separatrix it is given by $n(r)=n_{\text {edge }} \exp [-(r-a) / \lambda]$. The gap between the first wall and the current strap, containing the Faraday shield, is assumed to have negligible plasma in it. The cold plasma approximation uses a minimum density pedestal and collisionality $(v / \omega=0.1)$ to avoid lower hybrid resonances in the edge region.

Table 8. Plasma parameters for the ITER ignited case

\begin{tabular}{ll}
\hline Major radius & $7.75 \mathrm{~m}$ \\
Minor radius & $2.8 \mathrm{~m}$ \\
Toroidal field on axis & $6 \mathrm{~T}$ \\
Plasma current & $21 \mathrm{MA}$ \\
Central plasma density & $1.36 \times 10^{20} \mathrm{~m}^{-3}$ \\
Edge plasma density & $1.1 \times 10^{20} \mathrm{~m}^{-3}$ \\
Edge plasma e-folding distance, $\lambda$ & $0.02 \mathrm{~m}$ \\
Minimum density & $2.0 \times 10^{17} \mathrm{~m}^{-3}$ \\
Core profile exponent, $\alpha_{\mathrm{n}}$ & 0.15 \\
D:T & $0.5: 0.5$ \\
Scrape-off layer & $0.10,0.15,0.20 \mathrm{~m}$ \\
Frequency & $40,60,80 \mathrm{MHz}$ \\
\hline
\end{tabular}




\subsection{Strap Loading Results}

The antenna geometry used by RANT3D to calculate the plasma loading is specified in Table 1 and is identical in most respects with the geometry previously used in ITER/US/96/IV-RF-016. The changes in geometry between this report and ITER/US/96/IV-RF-01 are in the position of the septa (at 11 and $19 \mathrm{~cm}$ from the first wall; previously at 9 and $16 \mathrm{~cm}$ ). Half the driving current is placed on the front of the strap and half on the rear (at 6 and $11 \mathrm{~cm}$ from the front wall, respectively); the propagation velocity along the radiating section of the strap was taken to be $0.7 c$, and the poloidal current distribution was adjusted accordingly. The loading resistance per unit length $R^{\prime}$ is that value which gives the same total power for eight 1.16-m-long, lossy transmission lines with $Z_{0}=40 \Omega$ and $v_{\text {phase }}=0.7 c$, as the total power calculated by RANT3D.

The effect of the relative phase angle on plasma loading can be seen in Fig. 12, since reducing the phase angle lowers the wave number of the peak in the $k_{\|}$wave spectrum. This decreases the wave evanescence and increases the plasma loading. The plasma loading also increases exponentially with frequency as a consequence of the reduction in the evanescent layer, as discussed by Bhatnagar and Jacquinot ${ }^{9}$. An asymmetric plasma response with respect to poloidal mode number is also observed in our study, becoming more prominent at higher frequencies. The poloidal asymmetry is not as pronounced as that in Ref. [9] however, because the electrical length of the antenna never exceeds $\lambda / 4$.

The plasma loading is not very sensitive to strap width; Fig. 13 shows a slight decline in loading as the strap width is increased. Figure 14 shows the loading as the distance to the plasma, defined as the distance between the first wall and the plasma separatrix, is varied. The exponential decrease with distance for the dipole and current drive phasings is a consequence of both their spectra being dominated by a single wave number. The exponential decay rate is nearly proportional to the wave number of the dominant peak.

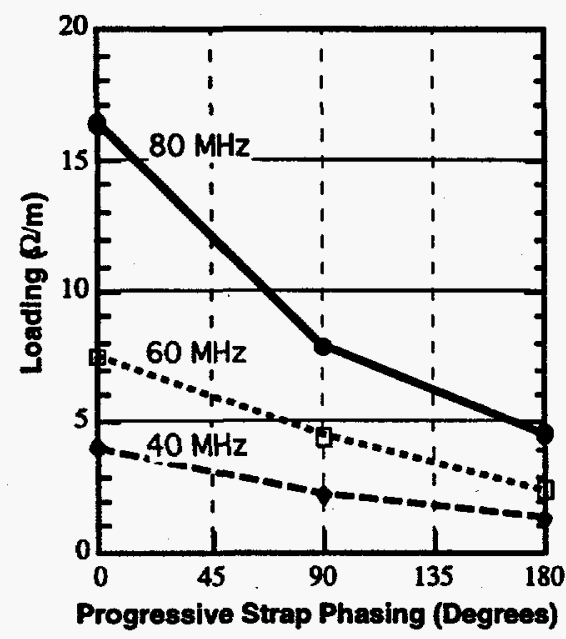

Fig. 12. Plasma loading vs array phase angle as function of frequency. Strap width is $18 \mathrm{~cm}$, and septa are 11 cm from first wall.

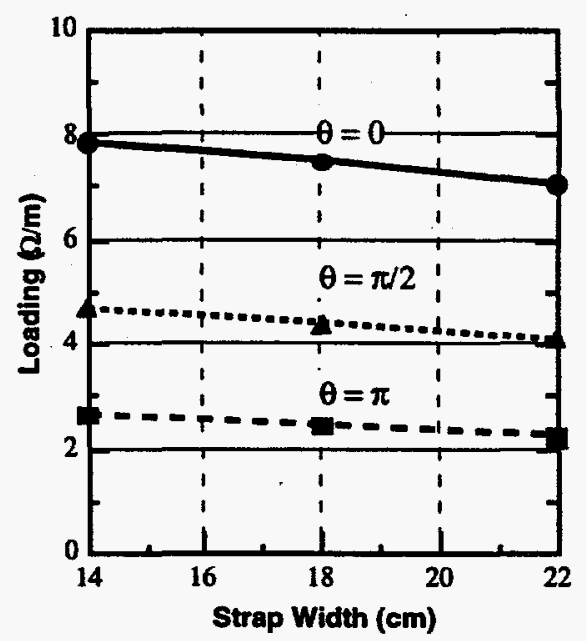

Fig. 13. Plasma loading vs strap width as function of array phase angle for $60-\mathrm{MHz}$ operation. Septa are $11 \mathrm{~cm}$ from first wall. 
The deviation from exponential decay for the monopole phasing is due to additional coupling of higher wave number spectral components at reduced plasma gaps; at the larger gaps these components die out before reaching a density at which they can propagate.

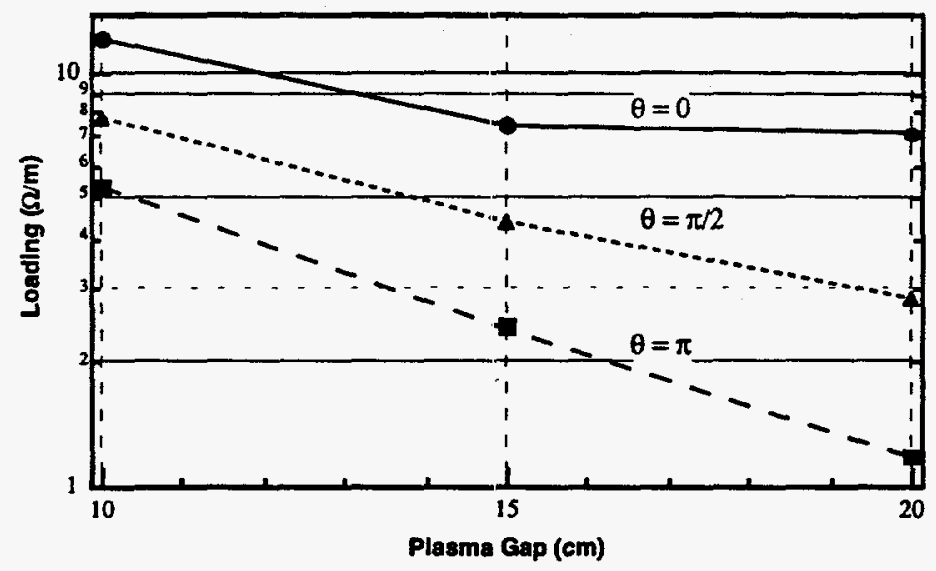

Fig. 14. Plasma loading vs plasma gap (first wall to separatrix) as function of array phase angle for $60 \mathrm{MHz}$. Straps are $18 \mathrm{~cm}$ wide, and septa are at $11 \mathrm{~cm}$.

\subsection{Current Drive Spectra}

The toroidal wave spectra for $90^{\circ}$ relative phasing between adjacent straps is shown in Fig. 15 for two different septa positions. As the solid septa ends are moved closer to the current straps, the array directivity drops slightly due to the induced return currents. The directivity, defined as the difference between the power radiated in the positive and negative directions, normalized to the total radiated power, decreases from 0.83 for septa ends located at $19 \mathrm{~cm}$ from the first wall, to 0.78 for septa ends at $11 \mathrm{~cm}$. This slight decrease in directivity is acceptable when compared to the decrease in the strap impedance and mutual coupling and the increase in Faraday shield strength afforded by positioning the septa ends closer to the first wall.

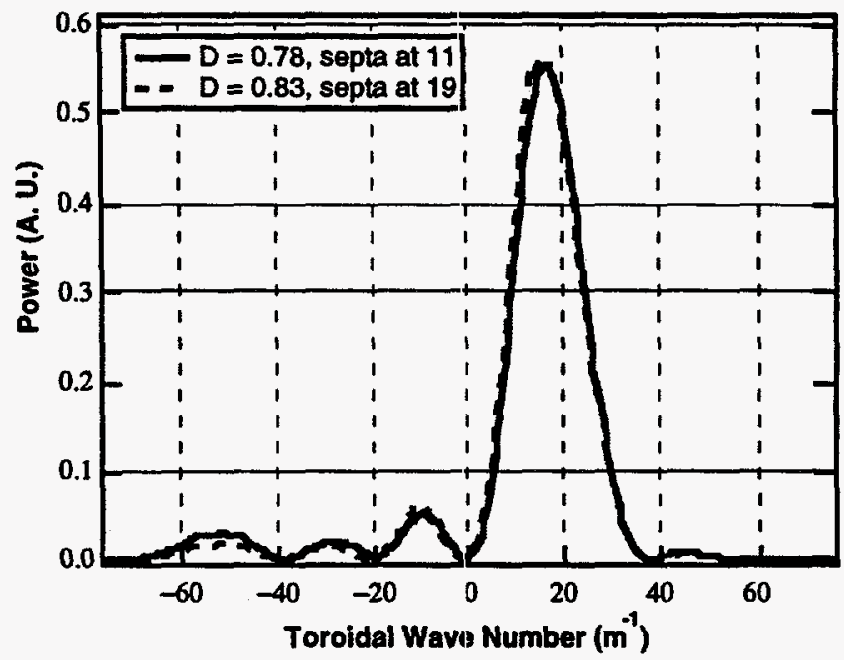

Fig. 15. Comparison of wave power spectrum and array directivity for $60 \mathrm{MHz}$ operation and $90^{\circ}$ relative phasing for two different septa positions. 


\section{INTEGRATED ANALYSIS}

\subsection{The Lossy Transmission Line Model}

A lossy transmission line model is used to compute the peak voltages and electric fields on the strap for a given power to the plasma. Standard nomenclature is used, with the propagation constant $\gamma$ and the characteristic impedance $Z_{0}$ of the strap given by

$$
\begin{aligned}
& \gamma=\sqrt{\left(j \omega L^{\prime}(\theta)+R^{\prime}(\theta)\right) j \omega C^{\prime}}=\alpha+j \beta \\
& Z_{0}=\sqrt{\frac{\left(j \omega L^{\prime}(\theta)+R^{\prime}(\theta)\right)}{j \omega C^{\prime}}} .
\end{aligned}
$$

Here $L^{\prime}, R^{\prime}$, and $C^{\prime}$ are those values shown in Tables $4-11$. Note that the values of $C^{\prime}$ in Table 7 are independent of phasing, but $L^{\prime}$ and $R^{\prime}$ are functions of the progressive phase angle $(\theta)$ between straps, with $R^{\prime}(\theta)$ coming directly from Tables 8-11 and $L^{\prime}$ calculated from Tables $4-6$ as

$$
\begin{aligned}
& L^{\prime}(0)=L_{0}^{\prime}(1+k), \\
& L^{\prime}(\pi / 2)=L_{0}^{\prime},
\end{aligned}
$$

and

$$
L^{\prime}(\pi)=L_{0}^{\prime}(1-k) .
$$

\subsection{Peak Voltage and Electric Fields}

The peak voltage on the strap is calculated for a total power delivered to the plasma of $12.5 \mathrm{MW}$ /port from $N$ full height straps (or $2 N$ half-height straps), using the voltage and current, $V_{\text {in }}$ and $I_{i n}$, at the ends (or inputs, in this model) of the straps.

or

$$
\begin{aligned}
& P_{\text {total }}=2 N\left[\frac{1}{2} \operatorname{Re}\left(V_{\text {in }} I_{\text {in }}^{*}\right)\right]=N \operatorname{Re}\left[\frac{V_{\text {in }} V_{\text {in }}^{*}}{Z_{\text {in }}^{*}}\right] \\
& \left|V_{\text {in }}\right|=\sqrt{\frac{P_{\text {total }}}{N \operatorname{Re}\left(1 / Z_{\text {in }}^{*}\right)}},
\end{aligned}
$$

where

$$
Z_{\text {in }}=Z_{0} \tanh (\not h) \text {. }
$$

The input impedance $Z_{\text {in }}$ at the top of the strap is calculated for a strap half-height $h$ of $0.55 \mathrm{~m}$; this is the distance from the virtual ground at the poloidal midpoint to the nominal end of the current strap. The maximum voltage on the radiating portion of the strap occurs at the end of the strap in virtually all cases. The one exception is the 4-cm-thick, 20cm-wide strap operating at $80 \mathrm{MHz}$ in monopole phasing; the combination of high frequency and low phase velocity puts the maximum voltage point at $0.548 \mathrm{~cm}$. The important point to note is that these antennas are operating close to a quarter-wavelength at $80 \mathrm{MHz}$. 
Tables 8-11 summarize the plasma loading ( $\left.\mathrm{R}^{\circ}\right)$, the maximum voltage on the end of the strap $\left(V_{\text {peak }}\right)$, the maximum values of the E-field components $\left(E_{\perp p e a k}\right.$ and $\left.E_{l p e a k}\right)$, and the strap's characteristic impedance $\left(Z_{\text {strap }}\right)$ and phase velocity $\left(\mathrm{v}_{\mathrm{ph}} / \mathrm{c}\right)$ as a function of antenna geometry, array phasing, and operating frequency. The nominal strap impedance $Z_{\text {strap }}$ and phase velocity $v_{p h} / c$ presented in these tables are simply the dominant components of the complex characteristic impedance and propagation constant defined in Eqs. (7.1) and (7.2):

$$
Z_{\text {strap }}=\operatorname{Re}\left(Z_{0}\right) \text {, }
$$

and

$$
v_{p h} / c=\omega / \beta c \text {. }
$$

\begin{tabular}{|c|c|c|c|c|c|c|c|c|}
\hline \begin{tabular}{|c|} 
Thickness \\
(cm)
\end{tabular} & $\begin{array}{c}\text { Width } \\
(\mathrm{cm})\end{array}$ & $\begin{array}{c}\begin{array}{c}\text { Phase } \\
\text { (degrees) }\end{array} \\
\end{array}$ & $\begin{array}{c}\mathbf{R}^{\prime} \\
(\Omega / \mathbf{m})\end{array}$ & $\begin{array}{c}\text { Vpeak } \\
(\mathbf{k}) \\
\end{array}$ & $\begin{array}{l}\mathrm{E}_{\perp} \text { peak } \\
(\mathrm{kV} / \mathrm{cm})\end{array}$ & $\begin{array}{l}\text { E } 1 \text { peak } \\
(\mathrm{kV} / \mathrm{cm})\end{array}$ & $\begin{array}{c}\mathbf{Z}_{\text {strap }} \\
(\Omega)\end{array}$ & $\mathbf{V}_{\mathbf{p h}} / \mathrm{c}$ \\
\hline 5.0 & $\begin{array}{l}14.0 \\
16.0 \\
18.0 \\
20.0 \\
22.0\end{array}$ & 180 & $\begin{array}{l}3.09 \\
2.96 \\
2.83 \\
2.73 \\
2.62 \\
\end{array}$ & $\begin{array}{l}51.7 \\
48.7 \\
46.2 \\
43.5 \\
41.0 \\
\end{array}$ & $\begin{array}{l}29.43 \\
27.73 \\
26.49 \\
25.00 \\
23.43 \\
\end{array}$ & $\begin{array}{l}17.29 \\
16.55 \\
16.13 \\
15.92 \\
15.49 \\
\end{array}$ & $\begin{array}{l}52.50 \\
46.02 \\
43.76 \\
40.08 \\
37.96 \\
\end{array}$ & $\begin{array}{l}0.602 \\
0.627 \\
0.644 \\
0.638 \\
0.655 \\
\end{array}$ \\
\hline 5.0 & $\begin{array}{l}14.0 \\
16.0 \\
18.0 \\
20.0 \\
22.0 \\
\end{array}$ & 0 & $\begin{array}{l}7.04 \\
6.92 \\
6.79 \\
6.61 \\
6.43 \\
\end{array}$ & $\begin{array}{l}42.6 \\
40.2 \\
38.6 \\
37.0 \\
35.8 \\
\end{array}$ & $\begin{array}{l}24.25 \\
22.90 \\
22.11 \\
21.26 \\
20.43 \\
\end{array}$ & $\begin{array}{l}14.25 \\
13.67 \\
13.47 \\
13.54 \\
13.51 \\
\end{array}$ & $\begin{array}{l}58.85 \\
52.09 \\
50.12 \\
46.54 \\
44.77 \\
\end{array}$ & $\begin{array}{l}0.590 \\
0.553 \\
0.562 \\
0.549 \\
0.555 \\
\end{array}$ \\
\hline 5.0 & $\begin{array}{l}14.0 \\
16.0 \\
18.0 \\
20.0 \\
22.0 \\
\end{array}$ & 0 & $\begin{array}{l}14.53 \\
14.40 \\
14.27 \\
13.99 \\
13.71 \\
\end{array}$ & $\begin{array}{l}35.3 \\
33.4 \\
32.3 \\
31.3 \\
30.6 \\
\end{array}$ & $\begin{array}{l}20.09 \\
19.01 \\
18.54 \\
17.97 \\
17.49 \\
\end{array}$ & $\begin{array}{l}11.80 \\
11.35 \\
11.29 \\
11.44 \\
11.56\end{array}$ & $\begin{array}{l}64.62 \\
57.57 \\
55.81 \\
52.24 \\
50.71 \\
\end{array}$ & $\begin{array}{l}0.536 \\
0.500 \\
0.504 \\
0.488 \\
0.489\end{array}$ \\
\hline 4.0 & $\begin{array}{l}14.0 \\
16.0 \\
18.0 \\
20.0 \\
22.0\end{array}$ & 180 & $\begin{array}{l}3.09 \\
2.96 \\
2.83 \\
2.73 \\
2.62\end{array}$ & $\begin{array}{l}53.5 \\
50.6 \\
47.8 \\
45.0 \\
42.5\end{array}$ & $\begin{array}{l}31.22 \\
29.68 \\
28.68 \\
27.11 \\
24.81\end{array}$ & $\begin{array}{l}20.57 \\
19.30 \\
19.14 \\
17.95 \\
17.99\end{array}$ & $\begin{array}{l}53.47 \\
48.75 \\
44.63 \\
40.92 \\
38.76\end{array}$ & $\begin{array}{l}0.651 \\
0.641 \\
0.634 \\
0.628 \\
0.645 \\
\end{array}$ \\
\hline 4.0 & $\begin{array}{l}14.0 \\
16.0 \\
18.0 \\
20.0 \\
22.0 \\
\end{array}$ & 90 & $\begin{array}{l}7.04 \\
6.92 \\
6.79 \\
6.61 \\
6.43 \\
\end{array}$ & $\begin{array}{l}44.1 \\
41.9 \\
40.0 \\
38.4 \\
37.1 \\
\end{array}$ & $\begin{array}{l}25.70 \\
24.60 \\
23.97 \\
23.09 \\
21.68 \\
\end{array}$ & $\begin{array}{l}16.93 \\
16.00 \\
15.99 \\
15.29 \\
15.72 \\
\end{array}$ & $\begin{array}{l}59.93 \\
55.25 \\
51.19 \\
47.59 \\
45.79 \\
\end{array}$ & $\begin{array}{l}0.580 \\
0.565 \\
0.552 \\
0.540 \\
0.545 \\
\end{array}$ \\
\hline 4.0 & $\begin{array}{l}14.0 \\
16.0 \\
18.0 \\
20.0 \\
22.0\end{array}$ & 0 & $\begin{array}{l}14.53 \\
14.40 \\
14.27 \\
13.99 \\
13.71\end{array}$ & $\begin{array}{l}36.5 \\
34.9 \\
33.5 \\
32.4 \\
31.7\end{array}$ & $\begin{array}{l}21.26 \\
20.48 \\
20.08 \\
19.50 \\
18.54\end{array}$ & $\begin{array}{l}14.01 \\
13.32 \\
13.40 \\
12.91 \\
13.44\end{array}$ & $\begin{array}{l}65.80 \\
61.09 \\
57.04 \\
53.47 \\
51.91\end{array}$ & $\begin{array}{l}0.528 \\
0.511 \\
0.495 \\
0.480 \\
0.480\end{array}$ \\
\hline
\end{tabular}

Table 8. Voltages and E-fields for $60-\mathrm{MHz}$ operation for septum at $19.5 \mathrm{~cm}$ 
Table 9. Voltages and E-fields for $60-\mathrm{MHz}$ operation for septum at $10.5 \mathrm{~cm}$

\begin{tabular}{|c|c|c|c|c|c|c|c|c|}
\hline $\begin{array}{c}\text { Thickness } \\
(\mathbf{c m})\end{array}$ & $\begin{array}{c}\text { Width } \\
(\mathbf{c m})\end{array}$ & $\begin{array}{c}\text { Phase } \\
(\text { degrees })\end{array}$ & $\begin{array}{c}\mathbf{R}^{\prime} \\
(\Omega / \mathbf{m})\end{array}$ & $\begin{array}{c}\mathbf{V}^{\text {peak }} \\
(\mathbf{k V})\end{array}$ & $\begin{array}{c}\mathbf{E}_{\perp} \text { peak } \\
(\mathbf{k V} / \mathbf{c m})\end{array}$ & $\begin{array}{c}\mathbf{E}_{\|} \text {peak } \\
(\mathbf{k V} / \mathbf{c m})\end{array}$ & $\begin{array}{c}\mathbf{Z}_{\text {strap }}(\Omega) \\
(\mathbf{\Omega})\end{array}$ & $\mathbf{V}_{\mathbf{p h}} / \mathbf{c}$ \\
\hline 5.0 & 14.0 & 180 & 2.64 & 53.2 & 30.24 & 17.76 & 51.12 & 0.679 \\
& 16.0 & & 2.53 & 49.7 & 28.28 & 16.88 & 44.64 & 0.646 \\
& 18.0 & & 2.42 & 46.7 & 26.75 & 16.29 & 42.23 & 0.667 \\
& 20.0 & & 2.32 & 43.6 & 25.02 & 15.93 & 38.46 & 0.665 \\
& 22.0 & & 2.20 & 40.7 & 23.25 & 15.37 & 36.14 & 0.688 \\
\hline 5.0 & 14.0 & 90 & 4.66 & 43.5 & 24.76 & 14.54 & 53.39 & 0.650 \\
& 16.0 & & 4.53 & 40.7 & 23.14 & 13.81 & 46.78 & 0.616 \\
& 18.0 & & 4.39 & 38.2 & 21.89 & 13.33 & 44.42 & 0.634 \\
& 20.0 & & 4.24 & 35.8 & 20.55 & 13.08 & 40.60 & 0.629 \\
& 22.0 & & 4.09 & 33.4 & 19.11 & 12.63 & 38.32 & 0.649 \\
\hline 5.0 & 14.0 & 0 & 7.82 & 36.3 & 20.66 & 12.14 & 55.59 & 0.624 \\
& 16.0 & & 7.64 & 34.0 & 19.34 & 11.54 & 48.85 & 0.590 \\
& 18.0 & & 7.46 & 32.0 & 18.35 & 11.17 & 46.52 & 0.605 \\
& 20.0 & & 7.25 & 30.1 & 17.28 & 11.00 & 42.65 & 0.599 \\
& 22.0 & & 7.03 & 28.2 & 16.13 & 10.66 & 40.40 & 0.615 \\
\hline 4.0 & 14.0 & 180 & 2.64 & 55.2 & 32.19 & 21.20 & 52.15 & 0.667 \\
& 16.0 & & 2.53 & 51.8 & 30.40 & 19.77 & 47.39 & 0.659 \\
& 18.0 & & 2.42 & 48.6 & 29.13 & 19.44 & 43.20 & 0.655 \\
& 20.0 & & 2.32 & 45.4 & 27.34 & 18.10 & 39.42 & 0.652 \\
& 22.0 & & 2.20 & 42.6 & 24.88 & 18.04 & 37.09 & 0.674 \\
\hline 4.0 & 14.0 & 90 & 4.66 & 45.3 & 26.44 & 17.42 & 54.58 & 0.637 \\
& 16.0 & & 4.53 & 42.5 & 24.98 & 16.24 & 49.77 & 0.628 \\
& 18.0 & & 4.39 & 39.9 & 23.95 & 15.98 & 45.55 & 0.621 \\
& 20.0 & & 4.24 & 37.5 & 22.57 & 14.94 & 41.74 & 0.616 \\
& 22.0 & & 4.09 & 35.2 & 20.57 & 14.91 & 39.47 & 0.633 \\
\hline 4.0 & 14.0 & 0 & 7.82 & 37.9 & 22.12 & 14.57 & 56.90 & 0.611 \\
& 16.0 & & 7.64 & 35.7 & 20.94 & 13.62 & 52.05 & 0.600 \\
& 18.0 & & 7.46 & 33.6 & 20.14 & 13.43 & 47.80 & 0.591 \\
& 20.0 & & 7.25 & 31.6 & 19.05 & 12.61 & 43.95 & 0.584 \\
& 22.0 & & 7.03 & 29.9 & 17.45 & 12.65 & 41.72 & 0.598 \\
\hline
\end{tabular}


Table 10. Voltages and E-fields for $40 \cdot \mathrm{MHz}$ operation for septum at $10.5 \mathrm{~cm}$

\begin{tabular}{|c|c|c|c|c|c|c|c|c|}
\hline $\begin{array}{c}\text { Thickness } \\
(\mathbf{c m})\end{array}$ & $\begin{array}{c}\text { Width } \\
(\mathbf{c m})\end{array}$ & $\begin{array}{c}\text { Phase } \\
(\text { degrees })\end{array}$ & $\begin{array}{c}\mathbf{R}^{\prime} \\
(\Omega / \mathbf{m})\end{array}$ & $\begin{array}{c}\mathbf{V}_{\mathbf{p e a k}} \\
(\mathbf{k V})\end{array}$ & $\begin{array}{c}\mathbf{E}_{\perp} \text { peak } \\
(\mathbf{k V} / \mathbf{c m})\end{array}$ & $\begin{array}{c}\mathbf{E}_{\|} \mathbf{p e a k} \\
(\mathbf{k V} / \mathbf{c m})\end{array}$ & $\begin{array}{c}\mathbf{Z}_{\mathbf{s t r a p}} \\
(\Omega)\end{array}$ & $\mathbf{V}_{\mathbf{p h}} / \mathbf{c}$ \\
\hline 5.0 & 14.0 & 180 & 1.41 & 49.1 & 27.91 & 16.40 & 51.12 & 0.679 \\
& 16.0 & & 1.35 & 46.0 & 26.20 & 15.64 & 44.64 & 0.646 \\
& 18.0 & & 1.29 & 43.2 & 24.74 & 15.07 & 42.24 & 0.667 \\
& 20.0 & & 1.24 & 40.3 & 23.16 & 14.75 & 38.46 & 0.665 \\
& 22.0 & & 1.18 & 37.5 & 21.41 & 14.15 & 36.15 & 0.688 \\
\hline 5.0 & 14.0 & 90 & 2.30 & 41.9 & 23.83 & 14.00 & 53.41 & 0.650 \\
& 16.0 & & 2.24 & 39.2 & 22.33 & 13.33 & 46.80 & 0.617 \\
& 18.0 & & 2.18 & 36.7 & 21.04 & 12.82 & 44.43 & 0.634 \\
& 20.0 & & 2.11 & 34.4 & 19.76 & 12.58 & 40.61 & 0.630 \\
& 22.0 & & 2.03 & 32.1 & 18.34 & 12.12 & 38.33 & 0.649 \\
\hline 5.0 & 14.0 & 0 & 4.23 & 33.5 & 19.04 & 11.19 & 55.65 & 0.625 \\
& 16.0 & & 4.13 & 31.5 & 17.93 & 10.70 & 48.91 & 0.590 \\
& 18.0 & & 4.02 & 29.6 & 16.98 & 10.35 & 46.57 & 0.605 \\
& 20.0 & & 3.92 & 27.8 & 15.98 & 10.18 & 42.71 & 0.599 \\
& 22.0 & & 3.81 & 25.0 & 14.87 & 9.83 & 40.46 & 0.615 \\
\hline 4.0 & 14.0 & 180 & 1.41 & 51.0 & 29.74 & 19.60 & 52.16 & 0.667 \\
& 16.0 & & 1.35 & 47.9 & 28.12 & 18.29 & 47.40 & 0.659 \\
& 18.0 & & 1.29 & 45.0 & 26.98 & 18.00 & 43.21 & 0.655 \\
& 20.0 & & 1.24 & 42.1 & 25.34 & 16.77 & 39.42 & 0.652 \\
& 22.0 & & 1.18 & 39.2 & 22.93 & 16.62 & 37.10 & 0.674 \\
\hline 4.0 & 14.0 & 90 & 2.30 & 43.7 & 25.49 & 16.79 & 54.59 & 0.637 \\
& 16.0 & & 2.24 & 41.0 & 24.06 & 15.65 & 49.78 & 0.628 \\
& 18.0 & & 2.18 & 38.4 & 23.05 & 15.38 & 45.56 & 0.621 \\
& 20.0 & & 2.11 & 36.1 & 21.74 & 14.39 & 41.75 & 0.616 \\
& 22.0 & & 2.03 & 33.9 & 19.77 & 14.34 & 39.48 & 0.633 \\
\hline 4.0 & 14.0 & 0 & 4.23 & 35.0 & 20.42 & 13.46 & 56.96 & 0.611 \\
& 16.0 & & 4.13 & 33.0 & 19.39 & 12.61 & 52.11 & 0.600 \\
& 18.0 & & 4.02 & 31.2 & 18.68 & 12.47 & 47.85 & 0.592 \\
& 20.0 & & 3.92 & 29.3 & 17.67 & 11.69 & 44.00 & 0.585 \\
& 22.0 & & 3.81 & 27.6 & 16.12 & 11.69 & 41.78 & 0.599 \\
\hline
\end{tabular}


Table 11. Voltages and E-fields for $80-\mathrm{MHz}$ operation for septum at $10.5 \mathrm{~cm}$

\begin{tabular}{|c|c|c|c|c|c|c|c|c|}
\hline $\begin{array}{c}\text { Thickness } \\
(\mathrm{cm})\end{array}$ & \begin{tabular}{|c|} 
Width \\
(cm)
\end{tabular} & \begin{tabular}{|c|}
$\begin{array}{c}\text { Phase } \\
\text { (degrees) }\end{array}$ \\
\end{tabular} & $\begin{array}{c}\mathbf{R}^{\prime} \\
(\Omega / \mathbf{m})\end{array}$ & $\begin{array}{c}\text { Vpeak } \\
(\mathbf{k V})\end{array}$ & \begin{tabular}{|l|}
$E_{\perp}$ peak \\
$(\mathrm{kV} / \mathrm{cm})$
\end{tabular} & \begin{tabular}{|l|}
$E_{\| \text {peak }}$ \\
$(\mathbf{k V} / \mathrm{cm})$
\end{tabular} & $\begin{array}{c}\text { Z }_{\text {strap }} \\
(\Omega)\end{array}$ & $\mathrm{V}_{\mathrm{ph} / \mathrm{c}}$ \\
\hline 5.0 & $\begin{array}{l}14.0 \\
16.0 \\
18.0 \\
20.0 \\
22.0 \\
\end{array}$ & 180 & $\begin{array}{l}4.95 \\
4.75 \\
4.54 \\
4.34 \\
4.14 \\
\end{array}$ & $\begin{array}{l}49.9 \\
46.1 \\
43.6 \\
40.7 \\
38.2 \\
\end{array}$ & $\begin{array}{l}28.35 \\
26.25 \\
24.99 \\
23.39 \\
21.82 \\
\end{array}$ & $\begin{array}{l}16.66 \\
15.67 \\
15.22 \\
14.90 \\
14.42 \\
\end{array}$ & $\begin{array}{l}51.12 \\
44.64 \\
42.24 \\
38.46 \\
36.15 \\
\end{array}$ & $\begin{array}{l}0.679 \\
0.646 \\
0.667 \\
0.664 \\
0.688 \\
\end{array}$ \\
\hline 5.0 & $\begin{array}{l}14.0 \\
16.0 \\
18.0 \\
20.0 \\
22.0 \\
\end{array}$ & 90 & $\begin{array}{l}8.32 \\
8.09 \\
7.86 \\
7.59 \\
7.31 \\
\end{array}$ & $\begin{array}{l}41.5 \\
38.2 \\
36.1 \\
33.8 \\
31.8 \\
\end{array}$ & $\begin{array}{l}23.59 \\
21.74 \\
20.71 \\
19.41 \\
18.19 \\
\end{array}$ & $\begin{array}{l}13.86 \\
12.98 \\
12.61 \\
12.36 \\
12.03 \\
\end{array}$ & $\begin{array}{l}53.41 \\
46.80 \\
44.43 \\
40.61 \\
38.33 \\
\end{array}$ & $\begin{array}{l}0.650 \\
0.616 \\
0.634 \\
0.629 \\
0.648 \\
\end{array}$ \\
\hline 5.0 & $\begin{array}{l}14.0 \\
16.0 \\
18.0 \\
20.0 \\
22.0 \\
\end{array}$ & 0 & $\begin{array}{l}17.02 \\
16.67 \\
16.32 \\
15.82 \\
15.31 \\
\end{array}$ & $\begin{array}{l}31.1 \\
28.6 \\
27.1 \\
25.4 \\
24.1 \\
\end{array}$ & $\begin{array}{l}17.70 \\
16.26 \\
15.55 \\
14.61 \\
13.78 \\
\end{array}$ & $\begin{array}{l}10.40 \\
09.71 \\
09.47 \\
09.31 \\
09.11 \\
\end{array}$ & $\begin{array}{l}55.65 \\
48.91 \\
46.57 \\
42.71 \\
40.46 \\
\end{array}$ & $\begin{array}{l}0.622 \\
0.588 \\
0.603 \\
0.596 \\
0.612 \\
\end{array}$ \\
\hline 4.0 & $\begin{array}{l}14.0 \\
16.0 \\
18.0 \\
20.0 \\
22.0\end{array}$ & 180 & $\begin{array}{l}4.95 \\
4.75 \\
4.54 \\
4.34 \\
4.14\end{array}$ & $\begin{array}{l}51.6 \\
48.3 \\
45.2 \\
42.3 \\
39.8\end{array}$ & $\begin{array}{l}30.08 \\
28.33 \\
27.11 \\
25.46 \\
23.25\end{array}$ & $\begin{array}{l}19.81 \\
18.42 \\
18.09 \\
16.85 \\
16.86\end{array}$ & $\begin{array}{l}52.16 \\
47.40 \\
43.21 \\
39.42 \\
37.10\end{array}$ & $\begin{array}{l}0.667 \\
0.659 \\
0.655 \\
0.652 \\
0.674\end{array}$ \\
\hline 4.0 & $\begin{array}{l}14.0 \\
16.0 \\
18.0 \\
20.0 \\
22.0\end{array}$ & 90 & $\begin{array}{l}8.32 \\
8.09 \\
7.86 \\
7.59 \\
7.31\end{array}$ & $\begin{array}{l}43.0 \\
40.2 \\
37.6 \\
35.2 \\
33.3\end{array}$ & $\begin{array}{l}25.08 \\
23.58 \\
22.52 \\
21.19 \\
19.47\end{array}$ & $\begin{array}{l}16.52 \\
15.33 \\
15.03 \\
14.03 \\
14.12\end{array}$ & $\begin{array}{l}54.59 \\
49.78 \\
45.56 \\
41.75 \\
39.48\end{array}$ & $\begin{array}{l}0.637 \\
0.627 \\
0.620 \\
0.615 \\
0.632\end{array}$ \\
\hline 4.0 & $\begin{array}{l}14.0 \\
16.0 \\
18.0 \\
20.0 \\
22.0\end{array}$ & 0 & $\begin{array}{l}17.02 \\
16.67 \\
16.32 \\
15.82 \\
15.31\end{array}$ & $\begin{array}{l}32.3 \\
30.2 \\
28.2 \\
26.5 \\
25.3\end{array}$ & $\begin{array}{l}18.83 \\
17.71 \\
16.92 \\
15.96 \\
14.77\end{array}$ & $\begin{array}{l}12.40 \\
11.51 \\
11.29 \\
10.57 \\
10.71\end{array}$ & $\begin{array}{l}56.96 \\
52.11 \\
47.85 \\
44.00 \\
41.78\end{array}$ & $\begin{array}{l}0.609 \\
0.598 \\
0.589 \\
0.582 \\
0.596\end{array}$ \\
\hline
\end{tabular}




\section{GEOMETRY OPTIMIZATION SUMMARY AND RECOMMENDATIONS}

Analysis of the results presented in Tables 8-11 leads to the following observations and recommendations:

1. Wide straps decrease the peak voltages and electric fields on the strap ends. The width of the current straps is the single most important parameter affecting the peak fields. The plasma loading decreases slightly with the strap width, but this is more than compensated for by the reduction in strap inductance. For voltage-limited operation, power delivered to the plasma is proportional to the plasma loading and inversely proportional to the square of the strap inductance. Wider straps combine lower strap impedance and higher phase velocity to delliver more power per strap volt.

2. Thick straps $(5 \mathrm{~cm})$ have lower peak voltages and electric fields than thin straps (4 $\mathrm{cm}$ ). The voltages are higher on the thin straps due to higher inductance and lower capacitance. Moreover, the electric field strength per strap volt is also higher on the thinner straps because of greater field enhancement at the strap ends.

3. Septum position has negligible effect on peak fields for given power. The plasma loading increases as the solid septa are placed further from the strap, but so does the strap inductance; the two effects nearly cancel each other out. Placing the solid septa flush with the back of the strap does not degrade the array directivity to any perceptible degree. The reduction in mutual coupling between straps and the improved Faraday shield strength recommend the septa to be positioned near the back of the straps.

4. Peak fields increase as the phase angle between adjacent straps increases. The strap impedance decreases as the relative phase angle increases, but the plasma loading decreases much more rapidly.

5. Peak fields as a function of frequency are slightly higher at $60 \mathrm{MHz}$ than at 40 or 80 $M H z$. As the operating frequency increases, the antenna becomes electrically longer and the voltage at the strap ends increases for a given current at the virtual ground. However, the plasma loading increases faster than linear with frequency, allowing the peak voltage on the strap at $80 \mathrm{MHz}$ to be somewhat lower than is needed at $60 \mathrm{MHz}$ for the same power.

\section{THE RADIAL FEEDERS AND STUB TUNERS}

Although the peak voltage on the strap is low for $40 \mathrm{MHz}$ operation due to the short electrical length of the antenna, the low plasma loading at this frequency implies a high peak current on the strap to achieve full power. Figure 16 shows the peak current on the strap as a function of frequency and phase for a $22-\mathrm{cm}$-wide, $5-\mathrm{cm}$-thick current strap. The high peak currents at $40 \mathrm{MHz}$ will be transformed into high peak voltages in the end-tuner sections of the RDL antenna; the magnitude of these peak voltages will be dependent on the characteristic impedance of the slow wave structure and of the radial feeds.

Figure 17 shows the peak voltage on the strap and the peak voltage in the RDL antenna circuit vs. frequency. The voltage peak is located at the end of the strap for 80$\mathrm{MHz}$ operation, at the entrance of the stub tuner for $60-\mathrm{MHz}$, and inside the stub tuner for 
40-MHz. The parameters chosen for this analysis are those used in Figs. 2 and 3: characteristic impedances of $50 \Omega$ for the radial feeder section and $20 \Omega$ for the stub tuner.

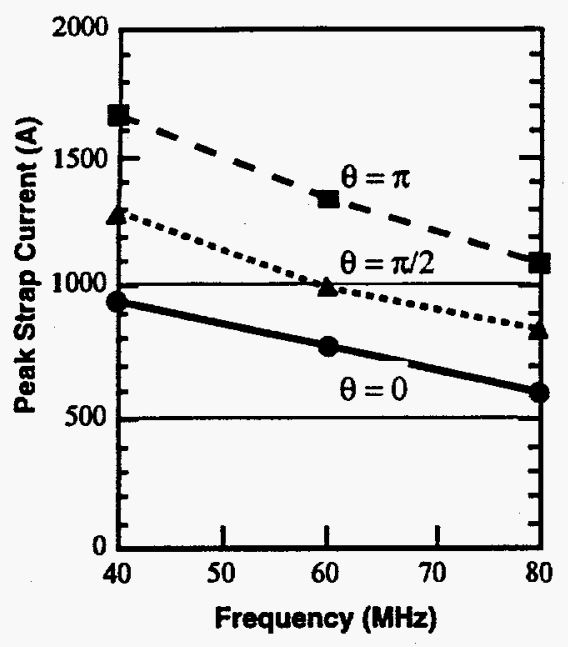

Fig. 16. Maximum instantaneous strap current vs frequency as function of relative phase angle between adjacen straps. Straps are $22 \mathrm{~cm}$ wide and $5 \mathrm{~cm}$ thick; septum position is at $10.5 \mathrm{~cm}$.

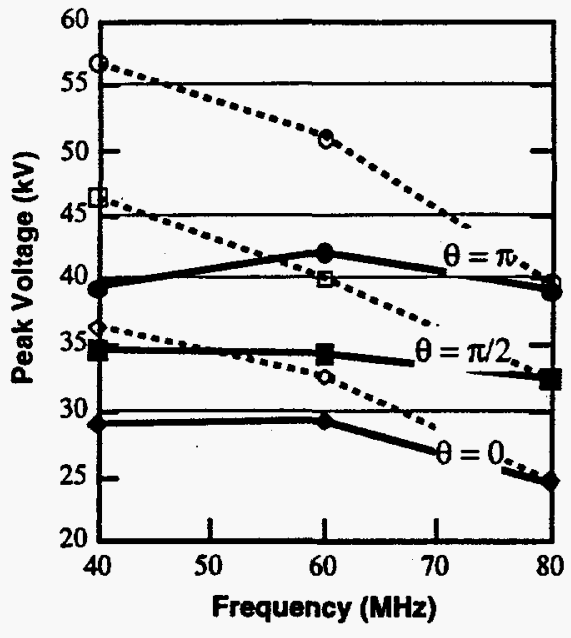

Fig. 17. Maximum voltages vs frequency as function of $\theta$. Solid curves are on strap; dashed curves are on RDL. Straps are $22 \mathrm{~cm}$ wide and $5 \mathrm{~cm}$ thick; septum position at $10.5 \mathrm{~cm}$. Feeder and stub tuner impedances are 50 and $20 \Omega$.

Figure 18 shows the peak currents in the RDL vs. frequency for full power operation at several different phasings. The peak currents occur at the moveable shorts in the $20 \Omega$ stub tuner sections; the magnitude of the currents at the shorts is inversely proportional to the characteristic impedance of the section. Therefore, increasing the impedance of this section will decrease this current and improve the reliability of the sliding short. However, the stub tuners have number of other design demands placed on them:

1. They must be able to withstand large $\mathrm{J} \times \mathrm{B}$ forces from plasma disruptions.

2. They must be compact enough to fit within the radial constraints of the blanket/vessel geometry, implying a slow wave structure with greatly reduced propagation velocity.

3. They must be able to hold off high voltages at the antenna end.

4. The moveable shorts must be capable of spanning sufficient electrical length to tune the antenna between 40 and $80 \mathrm{MHz}$.

Meeting all these design constraints is challenging, and flexibility in choosing the characteristic impedance of this section may be limited. We merely remark that reducing the current density at the sliding short should be kept in mind as a design goal. 


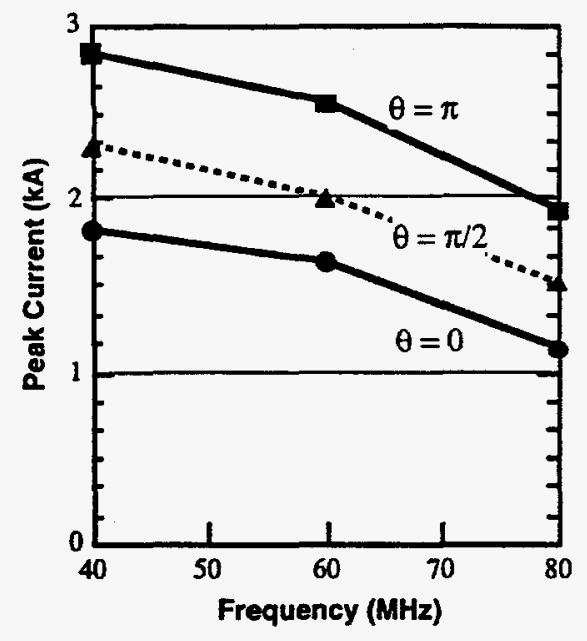

Fig. 18. Peak currents on RDL vs frequency as a function of array phasing. Peak currents occur at movable short at end of $20-\Omega$ stub tuners.
There is more flexibility in choosing the characteristic impedance of the radial feed section, however. The impedance of this section and the electric fields associated with it have been exarnined with the same 2-D Laplace techniques used for the current straps. Figure 19 shows $Z_{0}$ vs. width for a 5-cm-thick feeder section, for gap spacings of 2 to $4 \mathrm{~cm}$ between the feeder and the cavity end wall. Figure 20 shows the corresponding electric field, normalized to $1 \mathrm{~V}$ on the feeder. A 2-cm gap gives too high an electric field for reliable voltage holding; a gap on the order of 3 to $4 \mathrm{~cm}$ is recommended. A $4-\mathrm{cm}$ gap gives $Z_{0} \sim 40 \Omega$ for an 18 - to $22-\mathrm{cm}$-wide conductor, which is a fair match to the $Z_{0}$ of the radiating section of the strap. The peak electric field is fairly independent of strap width and is around $35 \mathrm{~V} / \mathrm{m}$ per feeder volt. For a peak voltage in the feeder of $-45 \mathrm{kV}$ at $40 \mathrm{MHz}$ (see Fig. 3), the corresponding peak electric field would be $\sim 16 \mathrm{kV} / \mathrm{cm}$. Note that the maximum field strength is basically the perpendicular field strength in this geometry; i.e., the field between the feeder and the cavity ends. However, the perpendicular-to-parallel field ratio is only 1.1 for a 4-cm gap; it is 1.3 for a $3-\mathrm{cm}$ gap and 1.6 for a $2-\mathrm{cm}$ gap.

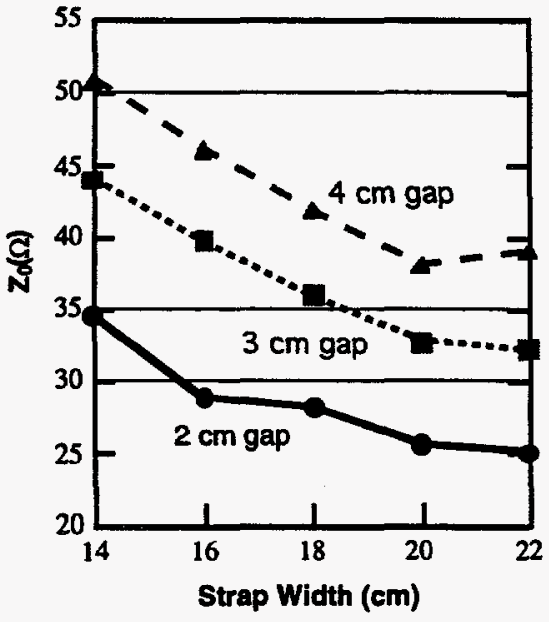

Fig. 19. Characteristic impedance of 5-cm-thick feeder sections vs width, as function of gap between feeder and cavity end walls.

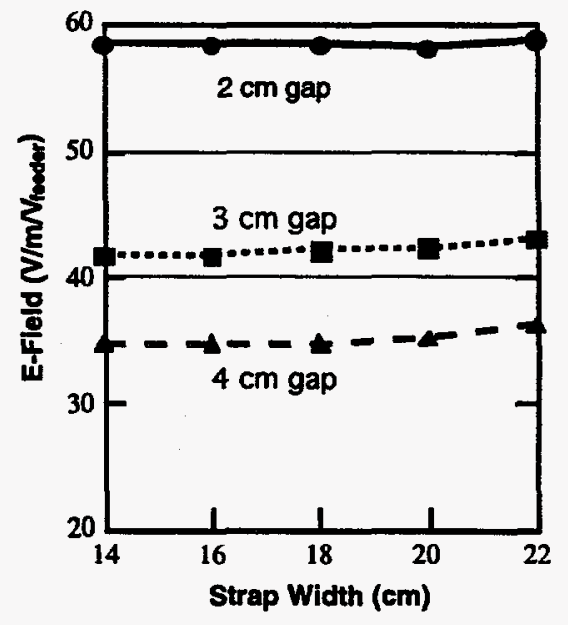

Fig. 20. Maximum electric field strength in $V / m$, normalized to feeder voltage, for feeder geometries of Fig. 119. 


\section{REFERENCES}

1. G. Bosia, "Status of ITER Antenna/VTL Design", 15th Proceedings of the Coordinating Committee on Fast Wave Current Drive and Heating and Joint ITER Working Meeting (D320, T235-8), Garching, Germany, 21-24 May 1996.

2. P. M. Ryan, F. W. Baity, R. H. Goulding, G. R. Haste, D. J. Hoffman, K. E. Rothe, J. H. Whealton, Fusion Engrg. Des. 24 (1994) 135.

3. Y. L. Ho, W. Grossman, A. Drobot, M. D. Carter, P. M. Ryan, D. B. Batchelor, 10th Top. Conf. on RF Power in Plasmas, AIP Conf. Proc. 289 (Boston, MA, 1993) 359.

4. M. D. Carter, D. A. Rasmussen, P. M. Ryan, G. R. Hanson, D. C. Stallings, D. B. Batchelor, T. S. Bigelow, A. C. England, D. J. Hoffman, M. Murakami, C. Y. Wang, J. B. Wilgen, J. H. Rogers, J. R., Wilson, R., Majeski, G. Schilling,Nucl. Fusion 36 (1996) 209.

5. D. A. D'Ippolito, J. R. Myra, P. E. Moroz and P. M. Ryan, "Analysis of RF Sheaths for the ITER Ion Cyclotron Antenna", Final Report on ITER Design Task D211.2 (ITER/US/96/IV-RF-03).

6. D. W. Swain and R. H. Goulding, Design of Fast Tuning Elements for the ITER ICH System, ORNL/TM-13230 (May 1996) amd ITER/US/96/IV-RF-01 (February 1996).

7. P. M. Ryan, K. E. Rothe, J. H. Whealton, T. D. and Shepard, Fusion Engrg. Des. 12 (1990) 37.

8. D. C. Stallings, D. B. Batchelor, C. Y. Wang, M. D. Carter, Bull. Am. Phys. Soc. 39 (1994) 1628.

9. V. P. Bhatnagar, and J. Jacquinot, Nucl Fus Lett, 34, No. 6 (June 1994) 886. 


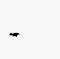

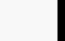

$\checkmark$

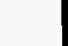




\section{APPENDIX A: DETERMINATION OF COUPLED TRANSMISSION LINE PARAMETERS FROM I, V CALCULATIONS}

\section{A.1. Coupled Transmission Line Analysis}

The following is based on the analysis and nomenclature of Lamalle et al. ${ }^{*}$

For a set of $n$ coupled transmission line sections, the voltage matrix $V$ and the current matrix I may be decoupled and expressed in the form of the telegraphist equations.

$$
\begin{aligned}
& V^{\prime}=\mathrm{ZI}, \\
& I^{\prime}=\mathrm{Y} \boldsymbol{V}, \\
& V^{\prime \prime}=\mathrm{Z} I^{\prime}, \\
& I^{\prime \prime}=\mathrm{Y} V^{\prime}, \\
& V^{\prime \prime}=\mathrm{ZY} \boldsymbol{V}, \\
& I^{\prime \prime}=\mathrm{YZI},
\end{aligned}
$$

where the derivatives are with respect to the position coordinate $x$ and the $n \times n$ impedance. The admittance matrices per unit length are

$$
\begin{gathered}
\mathbf{Z}=j \omega L^{\prime}+\boldsymbol{R}^{\prime}, \\
\mathbf{Y}=j \omega C^{\prime},
\end{gathered}
$$

where $L^{\prime}, R^{\prime}$, and $C^{\prime}$ matrices are the inductance, resistance, and capacitance per unit length.

To uncouple the modes, define new modal variables

$$
\begin{gathered}
\boldsymbol{V} \equiv \mathbf{K} \boldsymbol{V}_{\boldsymbol{m}} \\
\boldsymbol{I} \equiv \mathbf{L}_{\boldsymbol{m}},
\end{gathered}
$$

where $\mathrm{K}$ diagonalizes the $\mathrm{ZY}$ matrix and $\mathrm{L}$ diagonalizes the $\mathrm{YZ}$ matrix.

$$
\begin{gathered}
\mathbf{K} V_{m}{ }^{\prime \prime}=\mathbf{Z Y K} V_{m} \\
\boldsymbol{L}_{m}{ }^{\prime \prime}=\mathbf{Y Z L} I_{m} \\
V_{m}{ }^{\prime \prime}=\mathbf{K}^{-1} \mathbf{Z Y K} V_{m}=\mathbf{D} V_{m} \\
\boldsymbol{I}_{m}{ }^{\prime \prime}=\mathbf{L}^{-1} \mathbf{Y Z L} I_{m}=\mathbf{E} I_{m}
\end{gathered}
$$

$\mathbf{D}$ is a diagonal matrix of the eigenvalues of $\mathbf{Z Y}$, and $\mathbf{E}$ is a diagonal matrix of the eigenvalues of $\mathbf{Y Z}$. Note that for any two square matrices $\mathbf{A}$ and $\mathbf{B}$

$$
|\mathbf{A B}-\lambda \mathbf{I}|=|\mathbf{B A}-\lambda \mathbf{I}|:
$$

*P. U. Lamalle, A. M. Messiaen, and P. E. Vandenplas, IEEE Trans. Plasma Sci., PS-15, No. 1 (Feb. 1987) 60. 
that is, the eigenvalues of $\mathbf{A B}$ and $\mathbf{B A}$ are identical. Thus, $\mathbf{D}$ and $\mathbf{E}$ are the same diagonal matrix and

$$
\begin{gathered}
V_{m}{ }^{\prime \prime}=\mathrm{D} V_{m} \\
I_{m}{ }^{\prime \prime}=\mathrm{D} I_{m}
\end{gathered}
$$

The propagation matrix for these second order differential equations is

$$
\mathbf{G}=\sqrt{\mathbf{D}}=\operatorname{diag}\left(\gamma_{i}^{2}\right),
$$

where $\gamma_{i}$ is the complex propagation constant of mode $i$. The eigenmode solutions are

$$
\begin{gathered}
V_{m}=\exp (-\mathbf{G} x) A+\exp (+\mathbf{G} x) B, \\
I_{m}=\mathbf{Y}_{0}[\exp (-\mathbf{G} x) A-\exp (+\mathbf{G} x) B],
\end{gathered}
$$

where $Y_{0}$ is the characteristic admittance natrices for the eigenmodes (characteristic impedance matrix for the eigenmodes is $Z_{0}=Y_{0}^{-1}$ ) and $A, B$ are constants to be determined.

At $x=0$,

$$
\begin{gathered}
V_{m 0}=A+B, \\
I_{m 0}=\mathbf{Y}_{0}(A-B), \\
A=1 / 2\left(V_{m 0}+\mathbf{Z}_{0} I_{m 0}\right), \\
B=1 / 2\left(V_{m 0}-\mathbf{Z}_{0} I_{m 0}\right), \\
V_{m}=1 / 2[\exp (-\mathbf{G} x)+\exp \mathbf{G} x] V_{m 0}+1 / 2[\exp (-\mathbf{G} x)-\exp \mathbf{G} x] \mathbf{Z}_{0} I_{m 0}, \\
I_{m}=1 / 2 \mathbf{Y}_{0}[\exp (-\mathbf{G} x)-\exp \mathbf{G} x] V_{m 0}+1 / 2 \mathbf{Y}_{0}[\exp (-\mathbf{G} x)+\exp \mathbf{G} x] \mathbf{Z}_{0} I_{m 0}, \\
V_{m}=\mathbf{C} V_{m 0}-\mathbf{S Z} \mathbf{Z}_{0} I_{m 0}, \\
I_{m}=\mathbf{Y}_{0} \mathbf{C} \mathbf{Z}_{0} I_{m 0}-\mathbf{Y}_{0} \mathbf{S} V_{m 0},
\end{gathered}
$$

where $\mathbf{C} \equiv \cosh (\mathbf{G} x)$ and $\mathbf{S} \equiv \sinh (\mathbf{G} x)$. The characteristic impedance of the eigenmodes can be found from

$$
\begin{gathered}
V^{\prime}=\mathbf{K} V_{m}^{\prime}, \\
\mathbf{Z I}=\mathbf{Z} \mathbf{L} I_{m}=\mathbf{K} V_{m}^{\prime}, \\
I_{m}=\mathbf{L}^{-1} \mathbf{Z}^{-1} \mathbf{K} V_{m}^{\prime} .
\end{gathered}
$$

At $x=0$, there are no reflections when the impedance equals the characteristic impedance.

$$
\begin{gathered}
B=0 \Rightarrow V_{m 0}=\mathbf{Z}_{0} I_{m 0}, \\
V_{m 0}^{\prime}=\mathbf{G} V_{m 0}, \\
I_{m 0}=\left(\mathbf{L}^{-1} \mathbf{Z}^{-1} \mathbf{K G}\right) V_{m 0}=\mathbf{Y}_{0} V_{m 0}, \\
\mathbf{Z}_{0}=\mathbf{Y}_{0}^{-1}=\mathbf{G}^{-1} \mathbf{K}^{-1} \mathbf{Z L} .
\end{gathered}
$$


Equations (A.9) and (A.10) can convert the eigenmode solutions of Eqs. (A.26) and (A.27) to the actual voltages and currents.

$$
\begin{gathered}
V(x)=\mathbf{K C}(x) \mathbf{K}^{-1} V(0)-\mathbf{K S}(x) \mathbf{Z}_{0} \mathbf{L}^{-1} I(0), \\
I(x)=\mathrm{LZ}_{0}^{-1} \mathrm{C}(x) \mathbf{Z}_{0} \mathbf{L}^{-1} I(0)-\mathbf{L Z}_{0}^{-1} S(x) \mathbf{K}^{-1} V(0)
\end{gathered}
$$

Substitute the eigenmode characteristic impedance, Eq. (A.34), to obtain the current and voltage on the line in terms of the values at $x=0$.

$$
\begin{gathered}
V(x)=\mathbf{K C}(x) \mathbf{K}^{-1} V(0)-\mathbf{K S}(x) \mathbf{G}^{-1} \mathbf{K}^{-1} \mathbf{Z I}(0) \\
I(x)=\operatorname{YKGC}(x) \mathbf{G}^{-1} \mathbf{K}^{-1} \mathbf{Z I}(0)-\mathbf{Y K G S}(x) K^{-1} V(0)
\end{gathered}
$$

\section{A.2 Coupled Transmission Line Parameters from Currents and Voltages}

The determination of coupled transmission line parameters from calculated or measured currents and voltages is simplified in the case of end-grounded straps. For $V(0)=0$, Eqs. (A.35) and (A.36) become

$$
\begin{aligned}
& V\left(x_{0}\right)=-K S\left(x_{0}\right) Z_{0} \mathbf{L}^{-1} I(0), \\
& I\left(x_{0}\right)=L Z_{0}^{-1} \mathbf{C}\left(x_{0}\right) Z_{0} L^{-1} I(0) .
\end{aligned}
$$

The propagation matrix $\mathbf{G}$ is determined by the ratio of the currents at $x=0$ and $x=x_{0}$. Eq. (A.40) can be solved for $\mathrm{C}\left(x_{0}\right)$.

$$
\mathrm{C}\left(x_{0}\right)=\left[\mathrm{Z}_{0} \mathrm{~L}^{-1}\right] I\left(x_{0}\right) I^{-1}(0)\left[\mathbf{L Z}_{0}^{-1}\right]=\mathbf{Q}^{-1} I\left(x_{0}\right) I^{-1}(0) \mathbf{Q}
$$

Here $\mathbf{Q}$, a transformation matrix that diagonalizes the current ratio matrix, is the product of the matrix $L$ that relates the currents to the eigenmode currents in Eq. (A.10) and the characteristic admittance matrix $Y_{0}$ for those eigenmodes. At this point neither $L$ nor $Y_{0}$ can be uniquely specified.

We consider the lossless case in order to simplify the inverse operation

$$
\begin{gathered}
\mathbf{C}\left(x_{0}\right)=\operatorname{diag}\left[\cosh \left(\gamma_{i i}\right)\right]=\operatorname{diag}\left[\cos \left(-j \gamma_{i i} x_{0}\right)\right], \\
\mathbf{S}\left(x_{0}\right)=\operatorname{diag}\left[\sinh \left(\gamma_{i i}\right)\right]=j \cdot \operatorname{diag}\left[\sin \left(-j \gamma_{i i} x_{0}\right)\right], \\
\mathbf{G}=\left(j / x_{0}\right) \operatorname{acos}\left[\mathbf{C}\left(x_{0}\right)\right] .
\end{gathered}
$$
matrix.

The phase velocity of the eigenmodes is related to the inverse of the propagation

$$
\mathbf{V}_{\text {phase }}=(j \omega / c) \mathbf{G}^{-1} \text {. }
$$

Hence, the phase velocity or propagation matrix can be determined solely by the currents $I(0), I\left(x_{0}\right)$; the strap impedance matrix can be calculated using the strap voltage matrix $V\left(x_{0}\right)$ and the ground currents $I(0)$. The voltage transformation matrix $K$ is found from (A.39)

$$
\mathrm{K}=-V\left(x_{0}\right) I-1(0) \mathrm{LZ}_{0}^{-1} \mathrm{~S}-1\left(x_{0}\right)=-V\left(x_{0}\right) I-1(0) \mathrm{QS}-1\left(x_{0}\right)
$$


Finally, the impedance and admittance matrices which characterize the coupled transmission line model are determined from (A.34) and (A.13).

$$
\begin{gathered}
\mathbf{Z}=\mathbf{K G Z _ { 0 }} \mathbf{L}^{-1}=\mathbf{K G Q}^{-1}, \\
\mathbf{Y}=\mathbf{Z}^{-1} \mathbf{K}^{-1} \mathbf{D K}=\mathbf{Z}^{-1} \mathbf{K}^{-1} \mathbf{G}^{2} \mathbf{K} .
\end{gathered}
$$

The inductive and capacitive coupling matrices $L^{\prime}$ and $C^{\prime}$ are determined by equations (A.7) and (A.8) and the self-inductance of each of the straps are the diagonal elements of $\mathbf{Z}_{\text {strap }}$.

$$
\mathbf{Z}_{\text {strap }}=\sqrt{L^{\prime}\left(C^{\prime}\right)^{-1}}
$$


ORNL/TM-13370

Dist. Category UC-420

\section{INTERNAL DISTRIBUTION}

$\begin{aligned} \text { 1. } & \text { F. W. Baity } \\ \text { 2. } & \text { D. B. Batchelor } \\ \text { 3. } & \text { G. L. Bell } \\ 4 . & \text { T. S. Bigelow } \\ \text { 5. } & \text { B. A. Carreras } \\ \text { 6. } & \text { M. D. Carter } \\ \text { 7. } & \text { R. H. Goulding } \\ \text { 8. } & \text { D. J. Hoffman } \\ \text { 9. } & \text { E. F. Jaeger } \\ \text { 10. } & \text { S. L. Milora } \\ \text { 11-15. } & \text { P. M. Ryan }\end{aligned}$

$\begin{aligned} 16 . & \text { M. J. Saltmarsh } \\ 17 . & \text { J. Sheffield } \\ 18-22 . & \text { D. W. Swain } \\ 23 . & \text { N. A. Uckan } \\ 24-25 . & \text { Laboratory Records Department - RC } \\ 26 . & \text { Laboratory Records Department } \\ 27 . & \text { Central Research Library } \\ 28 . & \text { Document Reference Section } \\ 29 . & \text { Fusion Energy Division Library } \\ 30 . & \text { Engineering Technology/Fusion } \\ 31 . & \text { Energy Division Publications Office }\end{aligned}$

31. ORNL Patent Section

\section{EXTERNAL DISTRIBUTION}

32. Office of the Assistant Manager for Energy Research and Development, Department of Energy Field Office, Oak Ridge, P.O. Box 2000, Oak Ridge, TN 37831.

33. C. C. Baker, U.S. ITER Project Office, Univ. of California, San Diego, 9500 Gilman Drive, Bldg. 302, La. Jolla, CA 92093-0035.

34. V. Bhatnagar, JET Joint Undertaking, Abingdon, Oxfordshire, OX 14 EA, United Kingdom.

35. G. Bosia, ITER c/o Max-Planck Institut für Plasmaphysik, Boltzmannstr. 2, D-85748 Garching bei München, Germany.

36. J. D. Callen, Department of Nuclear Engineering, University of Wisconsin, Madison, WI 53706-1687.

37. R. Callis, General Atomics, Fusion Group 13/265, P. O. Box 85608, San Diego, CA 92186-9784.

38. R. W. Conn, Mechanical, Aerospace, and Nuclear Engineering Department, 6291 Boelter Hall, University of California, Los Angeles, CA 90024-1597.

39. N. A. Davies, Associate Director for Office of Fusion Energy Sciences, Office of Energy Research, ER-50, 19901 Germantown Road, Germantown, MD 20874-1290.

40. F. Durodie, Ecole Royale Militaire, 30, Avenue de la Renaissance, B-1000, Brussels, Belgium.

41. D. D'Ippolito, Lodestar Research Corporation, 2400 Central Avenue, P-5, Boulder, CO 80301.

42. F. Engelmann, Max-Planck Institut für Plasmaphysik, Boltzmannstr. 2, D85748 Garching bei München, Germany.

43. R. Freeman, General Atomics, Fusion Group, P. O. Box 85608, 13-269, San Diego, CA 92186-9784.

44. T. V. George, Office of Fusion Energy Sciences, Office of Energy Research, ER-531, 19901 Germantown Road, Germantown, MD 20874-1290.

45. C. Gormezano, JET Joint Undertaking, Abingdon, Oxfordshire, OX 14 EA, United Kingdom. 
46. R. J. Hawryluk, Princeton Plasma Physics Laboratory, P.O. Box 451, Princeton, NJ 08543.

47. J. C. Hosea, Princeton Plasma Physics Laboratory, P.O. Box 451, Princeton, NJ 08543.

48. J. Jacquinot, JET Joint Undertaking, Abingdon, Oxfordshire OX14, 3EA, United Kingdom.

49. H. Kimura, Japanese Atomic Energy Research Institute, Naka-machi, Nakagun, Ibaraki-ken 311-01, Japan.

50. R. Koch, Institut für Plasmaphysik, Forschungszentrum Jülich GmbH KFA, Postfach 1913, D-52425 Jülich, Germany.

51. D. M. Meade, Princeton Plasma Physics Laboratory, P.O. Box 451, Princeton, NJ 08543.

52. Riccardo Maggiora, Politechnico di Torino, Dipartimento di Elettronica, C.so Duca degli Abruzzi, 24, 10129 Torino, Italy.

53. W. Nevins, Lawrence Livermore National Laboratory, P. O. Box 808 (L-644), Livermore, CA 94551-9900.

54. J.-M. Noterdaeme, Max-Planck Institute for Plasmaphysics, D-85748, Garching, Germany.

55. E. Oktay, Office of Fusion Energy Sciences, Office of Energy Research, ER-55, 19901 Germantown Road, Germantown, MD 20874.

56. R. Parker, ITER c/o Max-Planck Institut für Plasmaphysik, Boltzmannstr. 2, D-85748 Garching bei München, Germany.

57. F. W. Perkins, ITER Co-center, 11025 North Torrey Pines Road, La Jolla, CA 92037.

58. R. Pinsker, Geneal Atomics, P. O. Box 85608, 13/254, San Diego, CA 92186-9784.

59. M. Porkolab, Massachusetts Institute of Technology, 167 Albany St., Bldg. NW16-288, Cambridge, MA 02139.

60. R. Prater, Genral Atomics, P. O. Box 85608, 13/268, San Diego, CA 921869784.

61. D. Remsen, General Atomics, P. O. Box 85608, San Diego, CA 92186-9784.

62. M. Roberts, Office of Fusion Energy Sciences, Office of Energy Research, ER-52, 19901 Germantown Road, Germantown, MD 20874.

63. W. M. Stacey, School of Nuclear Engineering and Health Physics, Georgia Institute of Technology, Atlanta, GA 30332.

64. H. S. Staten, Office of Fusion Energy Sciences, Office of Energy Research, ER-55 19901 Germantown Road, Germantown, MD 20874.

65. Y.Takase, Massachusetts Institute of Technology, 167 Albany St., Bldg. NW16-122, Cambridge, MA 02139.

66. K. I. Thomassen, Lawrence Livernore National Laboratory, P.O. Box 5511, Livermore, CA 94550.

67. P. Vandenplas, Ecole Royale Militaire, 30, Avenue de la Renaissance, B-1000, Brussels, Belgium.

68. T. Wade, JET Joint Undertaking, A.bingdon, Oxfordshire OX14, 3EA, United Kingdom.

69. F. Wesner, Max-Planck Institute for Plasmaphysics, D-85748, Garching, Germany.

70. K. L. Wilson, Sandia National Laboratories, P. O. Box 969, Livermore, CA 94551-0969.

71. J. R. Wilson, Princeton Plasma Physics Laboratory, P. O. Box 451, Princeton, NJ 08543.

72. Bibliothek, Max-Planck Institut für Plasmaphysik, Boltzmannstrasse 2, D-85748 Garching, Germany. 
73. Bibliothek, Institut für Plasmaphysik, KFA Jülich GmbH, Postfach 1913, D-5170 Jülich, Germany.

74. Bibliothek, KfK Karlsruhe GmbH, Postfach 3640, D-7500 Karlsruhe 1, Germany.

75. Bibliotheque, Centre de Recherches en Physique des Plasmas, Ecole Polytechnique Fédérale de Lausanne, 21 Avenue des Bains, CH-1007 Lausanne, Switzerland.

76. Bibliothèque, CEA/Cadarache, F-13108 Saint-Paul-lez-Durance Cedex, France.

77. Library, JET Joint Undertaking, Abingdon, Oxfordshire OX14 3EA, England.

78. Library, FOM-Instituut voor Plasmafysica, Rijnhuizen, Edisonbaan 14, 3439 MN Nieuwegein, The Netherlands.

79. Library, National Institute for Fusion Science, Chikusa-ku, Nagoya 464-01, Japan.

80. Library, International Centre for Theoretical Physics, P.O. Box 586, I-34100 Trieste, Italy.

81. Library, Centro Richerche Energia Frascati, C.P. 65, I-00044 Frascati (Roma), Italy.

82. Library, Plasma Physics Laboratory, Kyoto University, Gokasho, Uji, Kyoto 611, Japan.

83. Plasma Research Laboratory, Australian National University, P.O. Box 4, Canberra, A.C.T. 2601, Australia.

84. Library, Japan Atomic Energy Research Institute, Naka Fusion Research Establishment, 801-1 Mukoyama, Naka-machi, Naka-gun, Ibaraki-ken, Japan.

85. Library, Advanced Fusion Research Center, Research Institute for Applied Mechanics, Kyushu University 87, Kasuga, 816 Japan.

86-87. Office of Scientific and Technical Information, P. O. Box 62, Oak Ridge, TN 37831 . 